\title{
Wind speed and power characteristics for Jubail industrial city, Saudi Arabia
}

\author{
M. A. Baseera,b*, J.P. Meyerc, Md. M. Alam, S. Rehmane
}

aMechanical and Aeronautical Engineering Department, University of Pretoria, Pretoria, South Africa

bDepartment of Mechanical \& Manufacturing Engineering Technology , Jubail

Industrial College, Jubail, Saudi Arabia

E-mail: abaseer77@yahoo.com

*Corresponding author

cMechanical and Aeronautical Engineering Department, University of Pretoria, Pretoria, South Africa

E-mail: \osua.Meyer@up.ac.za

dInstitute for Turbulence-Noise-Vibration Interaction and Control, Shenzhen Graduate

School, Harbin Institute of Technology, Shenzhen 518055, China

E-mail: alamm28@yahoo.com

eCenter for Engineering Research, Research Institute, King Fahd University of

Petroleum and Minerals, Dhahran-31261, Saudi Arabia

E-mail: srehman@kfupm.edu.sa

\begin{abstract}
:
This paper presents the wind characteristics and resource assessment of the largest industrial base in the Middle East (Jubail industrial city) using measured hourly mean wind speed data at 10, 50 and $90 \mathrm{~m}$ above ground level (AGL) from 2008 to 2012. At respective heights, the mean wind speeds were found to be $3.34,4.79$ and $5.35 \mathrm{~m} / \mathrm{s}$. At 50 and $90 \mathrm{~m}$ AGL, the availability of wind speed above $3.5 \mathrm{~m} / \mathrm{s}$ was more than $75 \%$. The prevailing wind direction was from the north-west. The local wind shear exponent calculated using measured wind speed values at three heights was found to be 0.217. The mean wind power density values at measurement heights were 50.92, 116.03 and $168.46 \mathrm{~W} / \mathrm{m}^{2}$ respectively. The comparison of energy output from five commercially selected wind turbines of rated power ranging from 1.8 - 3.3 MW showed that the most efficient wind turbine is 3.0 MW rated power. The annual energy production from this turbine was estimated to be 6,285 MWh with a plant capacity factor of $25 \%$.
\end{abstract}

Keywords: Wind speed; wind rose; Weibull parameters; frequency distribution; wind shear exponent; capacity factor. 


\section{Introduction}

The cleanest sources of energy are those which use the natural resources of the earth. These sources are known as renewable sources of energy and will never die out unlike fixed reserves of fossil and nuclear fuels. Some of the common sources of renewable energies are wind, solar photovoltaic, solar thermal, hydro, wave, geothermal, and biomass. Wind is a very promising energy source and is receiving global recognition compared to other renewable energy sources, due to its low production, operation and maintenance cost and ease of maintenance, besides availability of efficient multimegawatt wind turbines.

Saudi Arabia is experiencing rapid population as well as industrial growth and resulting in ever increasing demand on power and water supplies. The total population of Saudi Arabia increased by more than five times within last four and half decades, from 5,772,000 in 1970 to 30,770,375 in 2014 [1]. The number of operating industries has increased by more than thirty times within last four decades, from 198 in 1974 to 6,471 in 2013 [2]. Total GDP (in constant prices) achieved by the manufacturing industries increased from US \$ 4 billion in 1975 to more than US \$ 45 billion at the end of 2013. Also, the growth rate of the manufacturing industries continued to increase throughout this period at an average of $6 \%$ per annum, which is considered one of the highest among the other economic sectors [2]. The region-wise share of the global installed wind power capacity is presented in Figure 1 [3]. The installed wind power capacity in Africa and Middle East is just 1\% of the global installed capacity of 369,596 MW by the end of year 2014. Therefore, Saudi Arabia is exploring alternate sustainable and reliable sources of energy for generating power and reducing consumption of the nation's fossil fuel reserves. So, it was determined that a balanced energy mix of alternative and conventional energy is strategically important to Saudi Arabia's long term prosperity, energy security and its leading position in the global energy market [4]. Wind energy utilization is one of the renewable energy options Saudi Arabia is considering seriously. 
Meteorological parameters; such as wind speed, wind direction, temperature, relative humidity, barometric pressure, global solar radiation etc.; are highly site and time dependent in general while wind speed and direction are highly fluctuating components among these parameters. Hence, it is necessary and critical to understand the wind speed variability and availability during different hours of the day and different months of the year for successful and profitable development and utilization of wind power. So, it is required to perform wind resource assessment of the site of interest to determine the feasibility of the wind farm development. Moreover, a small error in wind speed data gives a large error in energy yield calculations. Hence, accuracy in wind speed measurements can minimise the risk of huge investments [5].

The wind speed measurements are typically made at a different and lower height compared to the wind turbine hub height. The wind speed increases with height by a site-dependent power factor known as wind shear exponent. Wind speed can be extrapolated to the hub height by using the wind power law in conjunction with local wind shear exponent (WSE). If the estimated WSE is not accurate, the wind power law will lead to an error in the calculation of the wind speed at hub height and consequently the energy yield estimation [5]. Air density is another critical parameter that depends on air pressure and temperature at the site and directly affects the wind power density (WPD) and hence the energy yield estimates. Therefore, the actual air density should be calculated using the local pressure and temperature measurements for accurate energy output estimation [5].

To optimise the design of a wind turbine, data on speed range over which the turbine must operate to maximise energy extraction is required. This in turns requires the knowledge of the frequency distribution of the wind speed. Masseran et al. [6] presented nine frequency distribution functions suitable for fitting wind data: Weibull, Burr, Gamma, Inverse Gamma, Inverse Gaussian, Exponential, Rayleigh, Lognormal and Erlang. Rehman and Halawani [7] fitted the wind speed data of ten locations in Saudi Arabia to Weibull distribution function and concluded that this distribution 
accurately describes the wind data of this region. Similar studies elsewhere also claims that among all the frequency distribution functions that have been proposed for wind speed, the two-parameter Weibull distribution is most widely used to accurately describe wind regimes $[8,9,10]$.

Various studies on wind resource assessment are reported for Saudi Arabian locations. In 1986, Ansari et al, [11] developed wind atlas for Saudi Arabia by using measured wind speed at 8 to $12 \mathrm{~m}$ height above the ground level for 20 different locations. The hourly mean wind speed and direction data during the period 1970-1982 was used to develop the wind atlas. This atlas showed the seasonal average wind speed contours in different months over the entire kingdom. The long term annual mean wind speed was found to be below $4 \mathrm{~m} / \mathrm{s}$ in most of the regions. However, the data used were not reliable enough to determine the wind potential because, the sensors were mounted at a height of 8 to $12 \mathrm{~m}$ and the weather stations were located at low windy sites like airports. This wind atlas, which was the first effort towards wind resource assessment, also included the wind speed frequency distribution in different wind speed bins and the wind rose diagrams [11]. To better understand the wind power potential in the kingdom, Alawaji et al. [12] in 1996 performed wind speed measurements at 20, 30 and $40 \mathrm{~m}$ AGL at different locations in the Kingdom. In this study, six anemometers were installed on every wind tower, two each at 20,30 and $40 \mathrm{~m}$ height to get reliable results. The annual average wind speed at $40 \mathrm{~m}$ AGL at Arar, Dhahran, Gassim and Riyadh was reported to be 5.3, 4.5, 4.0 and $4.5 \mathrm{~m} / \mathrm{s}$ respectively [12]. Wind shear coefficients of wind speed at 20, 30, and $40 \mathrm{~m}$ AGL for Dhahran, Saudi Arabia was determined by Rehman and Al-Abbadi [5]. In this study, the energy yield was found to be around 120,000 MWh/year from a wind farm of $60 \mathrm{MW}$ installed capacity consisting of 40 wind turbines each of $1500 \mathrm{KW}$ rated power with a plant capacity factor of $24 \%$ [5]. In similar studies conducted by Shaahid et al. [13] at Taif, the wind speed was found to be less than $3 \mathrm{~m} / \mathrm{s}$ for $46 \%$ of the time during the year. The annual energy produced from 15 MW wind farm (from 25 commercially available wind turbines of $600 \mathrm{~kW}$ rated power 
capacity each at $50 \mathrm{~m}$ hub height) was around 20,000 MWh/year. The cost of energy in this analysis was found to be $0.0576 \mathrm{US} \$ / \mathrm{kWh}$. [13].

Some of the wind resource assessment studies reported for different countries were reviewed and discussed below. Prasad et al. [14] performed extensive literature survey on wind resource assessment (WRA) and discussed different WRA techniques. This methodology included preliminary wind survey to choose the best site for installing wind speed sensors, potential site selection, selecting the optimum wind turbine suitable for a site and the uncertainties involved in estimating the wind resource assessment using the different techniques. It was concluded that each WRA technique has its own advantages and selection of optimum technique is site dependent.

Fazelpour et al. [15] employed the Weibull probability distribution function for WRA using mean wind data at $10 \mathrm{~m}$ AGL over a six-year period at Tabriz and Ardabil, Iran. The hourly, diurnal, seasonal, monthly, and annual wind speed variations were analysed. The yearly values of the Weibull shape parameter vary from 1.81 to $2.13 \mathrm{~m} / \mathrm{s}$ with a mean of $1.99 \mathrm{~m} / \mathrm{s}$ for Tabriz and from 2.62 to $2.98 \mathrm{~m} / \mathrm{s}$ with a mean of $2.86 \mathrm{~m} / \mathrm{s}$ for Ardabil. Also, yearly values of the Weibull scale parameter vary from 3.35 to 4.45 $\mathrm{m} / \mathrm{s}$ with a mean of $4.18 \mathrm{~m} / \mathrm{s}$ for Tabriz and from 3.68 to $4.55 \mathrm{~m} / \mathrm{s}$ with a mean of $4.16 \mathrm{~m} / \mathrm{s}$ for Ardabil. The results show that the highest wind power potential occurs during months of August and July in Tabriz and during months of October and September in Ardabil.

Komleh et al. [16] analysed the wind speed data of Firouzkooh, Iran. For this purpose, 10-year period (2001-2010) wind data were analysed to calculate and estimate the wind power generation potential. Weibull and Rayleigh distribution functions were applied to find out the best fitting tool to the wind speed data. Results showed that Weibull and Rayleigh distribution functions can fit the values of wind speed well with almost the same coefficient of determination value of 0.97 . The average values of wind power 
density based on mean and root mean cube speed approaches were 203 and 248 $\mathrm{W} / \mathrm{m}^{2} /$ year, respectively.

Chandel et al. [17] assessed wind resource potential of the western Himalayan Indian state of Himachal Pradesh. Weibull parameters and WPD were determined for these locations. The highest daily mean wind speeds were observed in summers and lowest in winters in the region. Wind shear analysis showed that wind speeds at $30 \mathrm{~m}, 50 \mathrm{~m}, 80$ $\mathrm{m}$ and $100 \mathrm{~m}$ hub heights were found to increase by $10-17 \%, 26 \%, 34 \%$ and $39 \%$ respectively than those measured at $10 \mathrm{~m}$ height. The mean wind speed and WPD for the 12 locations were found to be in the range $3.9-4.7 \mathrm{~m} / \mathrm{s}, 4.7-5.8 \mathrm{~m} / \mathrm{s}, 5.7-7 \mathrm{~m} / \mathrm{s}, 6.2-7.7$ $\mathrm{m} / \mathrm{s}$ and 14.09-22. $\mathrm{W} / \mathrm{m}^{2}, 52.67-82.79 \mathrm{~W} / \mathrm{m}^{2}, 97.23-152.82 \mathrm{~W} / \mathrm{m}^{2}, 170.9-268.62 \mathrm{~W} / \mathrm{m}^{2}$, 223.37-351.1 W/ $\mathrm{m}^{2}$ at $30 \mathrm{~m}, 50 \mathrm{~m}, 80 \mathrm{~m}$ and $100 \mathrm{~m}$ heights respectively; thereby indicating fairly good wind potential for rooftop micro-wind turbines, battery charging, water pumping and wind power generation in western Himalayan region.

For wind resource assessment of Selcuk University campus in Turkey, one year wind data at three different heights was analysed [18]. Energy output from a 6 MW installed capacity wind farm composed of 1.0, 1.5, and 2.0 MW rated power wind turbines was calculated and reported by Faruk et al. [18]. The minimum basic payback period was found to be 6.44 years. Wind characteristics of six locations in Turkey were analysed using the wind speed data during the period 2000-2006 by Ucar et al. [19]. The annual mean wind speed of the six stations fell in the range from 5.9 to $8.7 \mathrm{~m} / \mathrm{s}$ at $10 \mathrm{~m}$ height. The mean annual value of Weibull shape parameter $k$ was between 1.71 and 1.96 while the annual value of scale parameter c was between 6.81 and $9.71 \mathrm{~m} / \mathrm{s}$. A technical assessment of electricity generation from four wind turbines of rated capacities of 600 $\mathrm{kW}, 1000 \mathrm{~kW}, 1500 \mathrm{~kW}$ and $2000 \mathrm{~kW}$ was made by Ucar et al. The annual energy obtained from $2000 \mathrm{~kW}$ rated power wind turbine was in the range of 4250 to 6900 MWh with a plant capacity factor between 24 to $39 \%$ at these six locations. 
Jowder [20] assessed the wind power potential of the kingdom of Bahrain by analysing hourly wind speed data for two years at $10 \mathrm{~m}$ height. The measured wind speed data at $10 \mathrm{~m}$ was extrapolated to $30 \mathrm{~m}$ and $60 \mathrm{~m}$ heights using the wind power law with wind shear exponent of 0.409 . The average annual wind power density was $114.54 \mathrm{~W} / \mathrm{m}^{2}$ at $10 \mathrm{~m}$ height, $433.29 \mathrm{~W} / \mathrm{m} 2$ at $30 \mathrm{~m}$ height and $816.70 \mathrm{~W} / \mathrm{m} 2$ at $60 \mathrm{~m}$ height. Fyrippis et al. [21] conducted the wind power potential assessment of Koronos village, Greece, using measured wind data at different heights and studied the wind characteristics using the Weibull and Rayleigh distribution functions. The annual mean wind speed was found to be $7.4 \mathrm{~m} / \mathrm{s}$ and the corresponding wind power density was $420 \mathrm{~W} / \mathrm{m}^{2}$ at $10 \mathrm{~m}$ above ground level. The results revealed that the Weibull model adequately fitted the actual experimental wind speed data.

The wind energy potential was estimated by Gao et al. [22] using five types of mixture probability functions for 11 years of measured wind data in Hong Kong. Based on the WRA, they identified and selected a potential offshore area for the development of the wind farm. The authors used multi-population genetic algorithm (MPGA) for getting minimum cost of energy (COE) with maximum power output. The study found annual offshore wind power potential of $112.81 \times 10^{8} \mathrm{kWh}$ which accounted for $25 \%$ of the total annual power consumption of Hong Kong in 2011. Onea et al. [23] presented the wind resource assessment of north-western side of the Black Sea using measured wind speed data over a period of 11 years. The analysis indicated that the Romanian coastal region has more wind energy potential during the winter season, with an average annual wind speed of about $9.7 \mathrm{~m} / \mathrm{s}$ at $80 \mathrm{~m}$ and a power density of $870 \mathrm{~W} / \mathrm{m}^{2}$. This study concluded that the north-western side of the Black Sea is a promising site for the wind farm development. Thus, wind resources assessment studies have been conducted in many parts of the world and reported in the literature. Some of the similar studies reported for countries like Korea [24], China [25], Malaysia [26], India [27], Kyrgyzstan [28], Pakistan [29], Oman [30], Turkey [31], Algeria [32], Iran [33], Egypt [34], Nigeria [35], 
Greece [36], Mexico [37], USA [38] and Venezuela [39] were reviewed to assess the methodology and techniques used for WRA.

This study aims at conducting a comprehensive and accurate wind resource assessment for the largest industrial city of Saudi Arabia for the first time and to calculate energy output based on a few commercially available wind machines. The size of this industrial city is expanding and is expected to be more than double in the next decade. The Kingdom has taken initiatives to supplement its existing fossil fuel based energy through renewable sources of energy particularly wind energy besides solar PV and solar thermal options [4]. This study will provide helpful information for wind power development program in this industrial city of Jubail.

\section{Site, equipment and data description}

In year 1933, geologists explored oil in Jubail, Saudi Arabia. In 1983, the largest engineering and construction project ever was started in Jubail to establish the biggest industrial base in the region. Presently, Jubail industrial city is host to more than 160 industrial enterprises and home to almost 70,000 residents. Jubail infrastructure is capable of running continuously without power failure in any of the existing facilities while meeting community requirements within high modern living standards where all the necessities of life and tourism and recreation are available.

To study the viability of wind power generation at Jubail industrial city, the historical wind data for five years was obtained from the Environment and Control Department (Royal Commission for Jubail and Yanbu). This governmental organisation is responsible for the maintenance, calibration and collection of meteorological data at Jubail industrial city. In the present study, wind characteristics and resource analysis is carried out using the data collected from weather station 1, shown in Fig. 2. Wind speed at this site was collected at three heights, 10, 50 and $90 \mathrm{~m}$. The latitude, longitude and Universal Transverse Mercator (UTM) coordinates of the weather station are given in Table. 1. The technical specifications of the meteorological sensors installed on all the 
seven wind towers at Jubail Industrial city are presented in Table 2. The list of weather parameters recorded are tabulated in Table 3. Monthly averaged metrological data (temperature, atmospheric pressure and relative humidity) at the weather data collection tower is given Table 4 .

The weather station at site 1 is located in the middle of Jubail Industrial area 1 . The weather station is mostly surrounded by plain terrain with industrial sheds of around 10 to $12 \mathrm{~m}$ height in south-west direction located $100 \mathrm{~m}$ away. There is a mobile phone network of around $30 \mathrm{~m}$ height tower located in the south-east direction located $150 \mathrm{~m}$ away. An industrial workers camp with around 8,000 residents is located in west direction from the weather station at a distance of $900 \mathrm{~m}$.

\section{Results and discussion}

The detailed wind data analysis over the entire period of data collection from 2008 to 2012 at Jubail industrial city is presented in this section. The complete set of ten minutes average wind speed values were first checked for erroneous values and completeness as per the existing standard practices. The annual mean wind speeds at 10, 50 and $90 \mathrm{~m}$ height were found to be $3.34,4.79$ and $5.35 \mathrm{~m} / \mathrm{s}$ with respective standard deviations of $0.14,0.17$, and 0.22 . The other meteorological parameters such as average ambient temperature, barometric pressure, global solar radiation, and relative humidity values near ground level were found to be $27.35{ }^{\circ} \mathrm{C}, 1008.39 \mathrm{mb}, 1550 \mathrm{kWh} / \mathrm{m}^{2}$, and $42 \%$; respectively. The derived parameters such as monthly average air density was found to vary between a minimum of $1.114 \mathrm{~kg} / \mathrm{m}^{3}$ and a maximum of $1.238 \mathrm{~kg} / \mathrm{m}^{3}$ with overall mean of $1.17 \mathrm{~kg} / \mathrm{m}^{3}$. The long term average values of WPD, calculated using ten minutes mean wind speed values at different heights were 50.92, 116.03, and 168.46 $\mathrm{W} / \mathrm{m}^{2}$. The annual energy production from a commercially available wind machine of 3 MW rated power was estimated to be 6,285 MWh/year. 


\subsection{Annual, seasonal and diurnal behaviour of mean wind speed}

The wind speed statistics (median, maximum, minimum, $75^{\text {th }}$ percentile and $25^{\text {th }}$ percentile) at $10 \mathrm{~m}$ height of all the seven weather stations at Jubail are illustarted in Fig. 3. Since these weather station lie within the radius of $15 \mathrm{kms}$ boundary, it can be observed from Fig. 3 that there is not much variation in wind speed statistics. Site 4 and 9 seems to have the highest mean wind speed. Out of all these seven sites, wind speed data at 10, 50 and $90 \mathrm{~m}$ height is available for site 1 only. The wind rose diagrams at 10, 50 and $90 \mathrm{~m}$ heights for site 1 are shown in Figs. 4, 5 and 6 respectively. The hourly mean values of wind speed and direction were used for entire period of data collection in these wind rose diagrams. It can be observed from these plots that the most prevailing wind direction at all the heights was from the north-west. The percentage of calm winds (wind speed less than $0.5 \mathrm{~m} / \mathrm{s}$ ) decreased with increasing height, i.e. 1.82, 0.61 and $0.56 \%$ at 10,50 and $90 \mathrm{~m}$ respectively.

The annual, seasonal and diurnal variations of hourly mean wind speed at 10, 50 and 90 $\mathrm{m}$ AGL over the entire period of data collection at station 1 are shown in Figs. 7, 8 and 9 respectively. Over the period of five years, the annual mean wind speeds at heights of measurements were $3.34,4.79$ and $5.35 \mathrm{~m} / \mathrm{s}$ with respective values of standard deviation of $0.14,0.17$ and 0.22 . At $90 \mathrm{~m}$, the annual average wind speed was always above $5.0 \mathrm{~m} / \mathrm{s}$ during the data collection period with a minimum of around $5.0 \mathrm{~m} / \mathrm{s}$ occurring in year 2010 as can be seen in Fig. 7. At 50 m, the annual mean wind speed always remained above $4.75 \mathrm{~m} / \mathrm{s}$ with maximum of more than $5.0 \mathrm{~m} / \mathrm{s}$ in 2011. This is an indication that wind turbine with $50 \mathrm{~m}$ and more hub heights can be used in the study area for wind farm development. These estimated mean speed values are comparable to the values reported in similar studies in Dhahran [5] and Bahrain [20]. The seasonal variation of wind speed shows that wind speed was the highest in the month of June and the lowest in October as shown in Fig. 8. This seasonal trend of wind speed coincides with the load pattern of Saudi Arabia and should be helpful in partial replacement of fossil fuel based energy generation by wind. Similar seasonal wind 
speed trend was reported for the location of Dhahran [5]. The monthly mean wind speed was more than 5.5 m/s during February, March, May, June, July, November and December months as seen from Fig. 8 which means that more power can be generated during these months from wind. The monthly mean wind speed values at 10, 50 and 90 $\mathrm{m}$ heights were $3.34,4.8$, and $5.35 \mathrm{~m} / \mathrm{s}$ with standard deviation of $0.33,0.42$ and 0.54 , respectively.

The diurnal variation showed two peaks at $90 \mathrm{~m}$, one from 04:00 hours to 07:00 hours and other from 13:00 to 16:00 hours with lows between 08:00 and 10:00 and 20:00 and 22:00 hours as observed from Fig. 9. Similar type of trend was noticed in the hourly mean values of wind speed at $50 \mathrm{~m}$ while at $10 \mathrm{~m}$, the wind speed started increasing from 00:00 hours and continued to increase till it reached a peak between 14:00 to 15:00 hours and then continued to decrease till 23:00 hours. The highest values of wind speed were 5.26, 6.28 and $6.33 \mathrm{~m} / \mathrm{s}$ at 15:00 hours corresponding 10, 50 and $90 \mathrm{~m}$ AGL while the lowest values were $2.29,4.19$ and $4.77 \mathrm{~m} / \mathrm{s}$ at around 21:00 to 22:00 hours, as seen from Fig. 9.

\subsection{Weibull parameters and wind frequency analysis}

The two-parameter Weibull distribution is frequently used to characterise wind behaviour because it provides a good representation of wind data [2, 3, 4]. This distribution function shows the probability of the wind speed in a $1 \mathrm{~m} / \mathrm{s}$ bins centered on a particular wind speed. The Weibull distribution function is expressed as [40]:

$$
P_{(v)}=\frac{k}{v}\left(\frac{v}{c}\right)^{k-1} \exp \left\{-\left(\frac{v}{c}\right)^{k}\right\},
$$

where $\mathrm{P}_{(\mathrm{v})}$ is the frequency of incidence of wind speed, $\mathrm{v}$. The scale factor, $\mathrm{c}$ in $\mathrm{m} / \mathrm{s}$, is indicative of mean wind speed and $\mathrm{k}$ is the dimensionless shape factor, which describes the shape and width of the distribution. 
The Weibull distribution is therefore determined by the parameters, $\mathrm{c}$ and $\mathrm{k}$. The cumulative Weibull distribution, $\mathrm{P}_{(\mathrm{v})}$, which gives the probability of the wind speed greater than the value, $\mathrm{v}$, is expressed as:

$$
P_{(v)}=\exp \left\{-\left(\frac{v}{c}\right)^{k}\right\},
$$

In this study, the Weibull distribution parameters, $\mathrm{c}$ and $\mathrm{k}$ are determined by maximum likelihood method. The seasonal values of both the scale factor (c) and shape parameter (k) are summarised in Table 5. The maximum values of shape parameter of 2.11, 2.80, and 2.43 were found in November, October and November at 10, 50, and $90 \mathrm{~m}$ while the corresponding minimum values of $1.52,1.96$, and 1.67 were observed in the month of July. The highest values of scale parameter ' $\mathrm{c}$ ' of $4.35,6.33$, and $6.74 \mathrm{~m} / \mathrm{s}$ were found in the months of March, February and June, and March at 10, 50, and $90 \mathrm{~m}$ height; respectively. The overall mean values of scale and shape parameters at measurement heights were $3.67,5.49,5.82 \mathrm{~m} / \mathrm{s}$ and $1.72,2.22,1.91$; respectively.

The actual wind speed frequency distribution and Weibull fit at 10, 50 and $90 \mathrm{~m}$ AGL are shown in Figs. 10, 11 and 12 respectively. It is evident from these figures that actual wind speed data is characterised well by the two-parameter Weibull distribution. The analyses of the Weibull percentage frequency distributions revealed that wind speed remained above $3.5 \mathrm{~m} / \mathrm{s}$ for $49.28,75.7$ and $77.7 \%$ of time at 10,50 and $90 \mathrm{~m}$ height respectively. This implies that at Jubail, a wind turbine with a hub height of $50 \mathrm{~m}$ and cut-in wind speed of $3.5 \mathrm{~m} / \mathrm{s}$ can produce energy for approximately $76 \%$ of the time and about $78 \%$ of the time with a hub height of $90 \mathrm{~m}$.

The values of scale factor, $\mathrm{c}$ increases with height, whereas no definite trend could be seen in the values of shape parameter, $\mathrm{k}$. However, highest value of shape parameter, $\mathrm{k}$ was found at $50 \mathrm{~m}$ height followed by $90 \mathrm{~m}$ and then $10 \mathrm{~m}$. 
3.3 Air density, wind power density (WPD), wind shear exponent (WSE)

The air density was estimated using the following expression:

$P=\frac{\rho}{R T} \quad\left(\mathrm{Kg} / \mathrm{m}^{3}\right)$

Where $P$ is the air pressure in Pascals, $R$ is the specific gas constant of air, $287.05 \mathrm{~J} / \mathrm{kg} . \mathrm{K}$ and $\mathrm{T}$ is the local air temperature in degrees Kelvin. The WPD is calculated using the well know following equation:

$\mathrm{WPD}=1 / 2 \rho \mathrm{V}^{3} \quad\left(\mathrm{~W} / \mathrm{m}^{2}\right)$

Where $\mathrm{V}$ is the ten minutes or hourly mean wind speed. The lowest air density was observed in July and the highest in January, as shown in Fig. 13. This simply means that air is lighter in summer time compared to that in winter season and hence less wind power density is expected in summer compared to that in winter. The mean wind power density values during the five years of data collection period at 10, 50, and $90 \mathrm{~m}$ AGL were found to be $50.92,116.03$, and $168.46 \mathrm{~W} / \mathrm{m}^{2}$ respectively. The annual, seasonal and diurnal variations of wind power density are shown in Figs. 14, 15, 16 respectively. The annual WPD trend followed almost the same trend as annual mean wind speed depicted in Fig. 7 with highest value of $186 \mathrm{~W} / \mathrm{m}^{2}$ in 2008 and a minimum of $146.2 \mathrm{~W} / \mathrm{m}^{2}$ in year 2010 at $90 \mathrm{~m}$ height as seen from Fig 14 . The seasonal variation of wind power density shows the highest values in June and the lowest in October as shown in Fig. 15. Higher values of WPD, (between 170 and $270 \mathrm{~W} / \mathrm{m}^{2}$ ), were observed during January to March, May to July and November to December while less than 150 $\mathrm{W} / \mathrm{m}^{2}$ during rest of the months in the year at $90 \mathrm{~m}$. Similar seasonal trends were observed at 50 and $10 \mathrm{~m}$ heights with lesser magnitudes of WPD. The diurnal variation of WPD showed clearly two peaks first between 03:00 and 07:00 hours and the second between 13:00 and 15:00 hours at $90 \mathrm{~m}$ height as shown in Fig. 18. However, the first peak was not distinctive at 50 while the second peak was still visible and that too during the same time duration. Finally, at $10 \mathrm{~m}$, the WPD started increasing right from 
00:00 hours and after reaching its peak between 13:00 to 15:00 hours started decreasing towards the end of the day as seen from Fig. 16.

Wind shear is defined as the exponent a (alpha) in the power law equation that relates wind speeds at two different heights. It is important to perform WSE calculations only where valid upper and lower wind speed measurements are available for a given time interval. In practice, it has been found that a varies with elevation, time of day, season, temperature, terrain, and atmospheric stability. The larger the exponent the larger the vertical gradient in the wind speed. Although the power law is a useful engineering approximation of the average wind speed profile but actual profiles tend to deviate from this relationship. The wind shear profile obtained using the long term mean value of wind speed at three heights is shown in Fig. 17.

The following equation was used to estimate the wind shear exponent (WSE), a:

$$
\alpha=\frac{\ln \left(V_{2}\right)-\ln \left(V_{1}\right)}{\ln \left(Z_{2}\right)-\ln \left(Z_{1}\right)}
$$

Where $V_{1}$ and $V_{2}$ are the wind speeds at heights $Z_{1}$ and $Z_{2}$ respectively. Equation (5) was used to find the annual, seasonal and diurnal variations of wind shear exponent as shown in Figs. 18, 19 and 20. The annual values of WSE varied between 0.18 and 0.25 calculated based on WS at 10 and 50 m with an increasing trend from 2008 to 2012, as shown in Fig. 18. However the WSE values calculated using WS values at 10 and $90 \mathrm{~m}$ varied between 0.20 and 0.24 with almost constant values of WSE of a little more than 0.20 for all the years except 2009. Largest variation in WSE values, calculated using WS values at 50 and $90 \mathrm{~m}$, was observed with a minimum of 0.10 in 2012 and a maximum of 0.28. 2009, as can be seen from Fig. 18. The monthly mean values of WSE calculated using WS data between 10 and $50 \mathrm{~m}$ and 10 and $90 \mathrm{~m}$ showed a decreasing trend from January May with a persistence till August and then an increasing trend towards the end of the year, as shown in Fig. 19. However, the WSE values obtained using WS between 50 and $90 \mathrm{~m}$ did not show a seasonal change. The diurnal variation of the WSE 
showed lowest value during daytime, i.e. from 09:00 to 15:00 hours, mainly due to high temperature and turbulence. The hourly mean values of WSE, based on WS between 10 and $50 \mathrm{~m}$ and 10 and $90 \mathrm{~m}$, showed almost same values during 00:00 to 06:00 hours and a sudden decrease in a short duration of 3 hours from 06:00 to 09:00 hours while lowest and almost constant values during 09:00 to 17:00 hours, as can be seen from Fig. 20. These WSE values again started increasing from 18:00 till mid night. The WSE values estimated based on WS values between 50 and $90 \mathrm{~m}$ behaved a little differently with an increasing trend from 00:00 till 07:00 hours and then a decreasing trend 10:00 hours and lowest and almost constant values from 11:00 16:00 hours. An increasing trend was seen between 17:00 and 20:00 hours and then again decreasing towards mid night.

\subsection{Energy output analysis}

To find the energy output from selected wind turbines, frequency of occurrence of wind speed in different bins was determined. This wind speed frequency at different hub heights was determined by vertical extrapolation of wind speed using the local WSE value of 0.217 in the present case. The technical specifications of wind turbines (WT1, WT2, WT3, WT4, and WT5) used in this study are summarised in Table 6. The power curves of all the selected wind turbines are shown in Fig. 21. Table 7 summarises the

number of hours the wind speed remained in different wind speed bins per year for Jubail at different heights. This table also includes the power curves data of all the selected wind turbines [36]. Finally, the power output in kWh for each wind speed bin, total power output per year and the plant capacity factor (PCF) for each of the five selected wind machines is also presented in this table. It can be observed from the \% PCF data that the most efficient of the selected wind turbines was WT2 with rated power of $3 \mathrm{MW}$ and a PCF of $25 \%$. As per the present calculations, the maximum annual energy output of 6,285 MWh/year can be achieved from this turbine (WT2). Wind turbine WT1 with annual energy yield of 6,367 MWh and a PCF of 23.3\% was found to be the second best turbine for Jubail industrial city. The third best turbine was 
WT4 with annual energy yield of $3,486 \mathrm{MWh}$ and a PCF of $22 \%$. A PCF of $24 \%$ was reported in similar studies performed in Dhahran [5]. The comparison of the seasonal energy output from the selected wind machines is shown in Fig. 22. As seen from this figure, minimum monthly mean wind power was obtained in the months of April and October whiles the maximum in March. In general, an increasing trend was observed in monthly power output from all turbines from January till March and then a decreasing trend towards end of the year except for dips in April and October.

\section{Conclusions}

The following main conclusions can be drawn from the wind resource assessment for Jubail Industrial City:

$\checkmark$ At 10, 50 and $90 \mathrm{~m}$ AGL, the annual mean wind speeds over the period 2008-2012 were $3.34,4.79$ and $5.35 \mathrm{~m} / \mathrm{s}$ respectively.

$\checkmark$ There was not much variation in mean annual wind speed. The monthly variation shows the wind speed was the highest in June and the lowest in October. The diurnal variation shows the wind speed to be high during daytime and low during night-time from 2008 - 2012.

$\checkmark$ Most prevailing wind direction at all three heights was from the north-west.

$\checkmark$ The percentage of calm winds (wind speed less than $0.5 \mathrm{~m} / \mathrm{s}$ ) decreased with increasing height, i.e. $1.82,0.61$ and $0.56 \%$ at 10,50 and $90 \mathrm{~m}$ respectively.

$\checkmark$ The Weibull parameter, c, was the highest in the month of March and the lowest in the month of October at all the measurement heights.

$\checkmark$ The wind speed was found to be above $3.5 \mathrm{~m} / \mathrm{s}$ for $49.3,75.7$ and $77.7 \%$ of time at 10 , 50 and $90 \mathrm{~m}$ height respectively. The air density was observed to be the lowest in the month of July and the highest in the month of January.

$\checkmark$ The wind shear exponent obtained from power law fitting of the wind shear profile was 0.217. The diurnal variation showed low values of WSE during daytime, i.e. 
from 9:00 AM to 3:00 PM. The seasonal variation of wind shear exponent did not show any specific pattern.

$\checkmark$ The annual energy production from a commercially available wind turbine WT1 of 3 MW rated power was estimated to be 6,285 MWh with a PCF of $25 \%$.

\section{Acknowledgement:}

The authors would like to acknowledge Jubail industrial college, Royal commission for Jubail and Yanbo, Saudi Arabia for providing the weather data used in this study. The authors would also like to acknowledge the technical support and guidance provided by King Fahd University of Petroleum and Minerals, Dhahran, Saudi Arabia and University of Pretoria, Pretoria, Republic of South Africa.

\section{References}

[1] Government annual report on Demographic survey by Central Department of Statistics and Information of Saudi Arabia, 2014. Available at: <http://www.cdsi.gov.sa/english/index.php $>$ (Accessed 16.05.2015)

[2] Government annual report on Industrial growth of Saudi Arabia by Saudi industrial Development Fund, 2014. Available at: $<$ http:// www.sidf.gov.sa/En/Pages/default.aspx> (Accessed 16.05.2015)

[3] Statistics from the Global wind Energy Council (GWEC). Available at: <http://www.gwec.net/global-figures/graphs > (Accessed 16.05.2015)

[4] The Vision, King Abdullah City of Atomic and Renewable energy (KACARE). Available at: <http://www.kacare.gov.sa/en/?page_id=84> (Accessed 16.05.2015)

[5] Rehman S. and Al-Abbadi, N. M. Wind Shear Coefficients and Energy Yield for Dhahran. Renewable Energy 2007; 32(5): 738 - 749. 
[6] Nurulkamal Masseran, Ahmad Mahir Razali, Kamarulzaman Ibrahim, Azami Zaharim and Kamaruzzaman Sopian. Research Journal of Applied Sciences, Engineering and Technology 2013; 6(10): 1774-1779.

[7] Rehman S, Halawani TO, Husain T. Weibull parameters for wind speed distribution in Saudi Arabia. Solar Energy 1994; 53(6): 473-479.

[8] Rehman, S. and Halawani, T. O. Statistical characteristics of wind in Saudi Arabia, Renewable Energy 1994; 4(8): 949-956.

[9] Islam, M.R., R. Saidur, and N.A. Rahim. Assessment of wind energy potentiality at Kudat and Labuan, Malaysia using Weibull distribution function. Energy 2011; 36(2):985-92.

[10] Rehman, S., A. M. Mahbub Alam, J. P. Meyer, L. M. Al-Hadhrami. Wind speed characteristics and resource assessment using Weibull Parameters. International Journal of Green Energy 2012; 9: 800-814.

[11] Ansari J, Madni IK, Bakhsh H. Saudi Arabian wind energy atlas. Riyadh, Saudi Arabia: KACST 1986: 1-27.

[12] S.H. Alawaji, N.N. Eugenio, U.A. Elani. Wind energy resource assessment in Saudi Arabia. Part II: Data Collection and Analysis. Renewable energy 1996; 9 (4): 818821.

[13] S.M. Shaahid, Luai M. Al-Hadhrami, M.K. Rahman. Potential of Establishment of Wind Farms in Western Province of Saudi Arabia. Energy Procedia 2014; 52: 497505.

[14] R.D. Prasad, R.C. Bansal, M. Sauturaga. Some of the design and methodology considerations in wind resource assessment. IET Renewable Power Generation 2009; 3 (1): 53-64.

[15] Fazelpour, Farivar; Soltani, Nima; Soltani, Sina; Rosen, Marc A. Assessment of wind energy potential and economics in the north-western Iranian cities of Tabriz and Ardabil. Renewable and Sustainable Energy Reviews 2015; 45; 87-99. 
[16] Pishgar-Komleh, S.H; Keyhani, A; Sefeedpari, P. Wind speed and power density analysis based on Weibull and Rayleigh distributions (a case study: Firouzkooh county of Iran). Renewable and Sustainable Energy Reviews 2015; 42; 313-322.

[17] Chandel, S.S; Ramasamy, P; Murthy, K.S.R. Wind power potential assessment of 12 locations in western Himalayan region of India. Renewable and Sustainable Energy Reviews 2015; 39; 530-545.

[18] Faruk Kose, Muharrem Hilmi Aksoy, Muammer Ozgoren. An Assessment of Wind Energy Potential to Meet Electricity Demand and Economic Feasibility in Konya, Turkey. International Journal of Green Energy 2014; 11 (6): 559-576.

[19] Ucar A, Balo F. Evaluation of wind energy potential and electricity generation at six locations in Turkey. Applied Energy 2009; 86: 1864-1872.

[20] ALF Jowder. Wind power analysis and site matching of wind turbine generators in Kingdom of Bahrain, Applied Energy 2009; 86: 538-545.

[21] Fyrippis I, Axaopoulos JP, Panayiotou G. Wind energy potential assessment in Naxos Island Greece. Applied Energy 2010; 87: 577-586.

[22] Xiaoxia Gao, Hongxing Yang, Lin Lu. Study on offshore wind power potential and wind farm optimization in Hong Kong. Applied Energy 2014; 88(5): 1848-1856.

[23] Florin Onea, Eugen Rusu. An evaluation of the wind energy in the north-west of the black sea. International Journal of Green Energy 2014; 11(5): 465-487.

[24] Myung Eun Leea, Gunwoo Kimb, Shin-Taek Jeong, Dong Hui Koc, Keum Seok Kang. Assessment of offshore wind energy at Younggwang in Korea. Renewable and Sustainable Energy Reviews 2013; 21: 131-141.

[25] Jie $\mathrm{Wu}$, Jianzhou Wang, Dezhong Chi. Wind energy potential assessment for the site of Inner Mongolia in China. Renewable and Sustainable Energy Reviews 2013; 21: 215-228.

[26] M. Irwanto, N. Gomesh, M.R. Mamat, Y.M. Yusoff. Assessment of wind power generation potential in Perlis, Malaysia. Renewable and Sustainable Energy Reviews 2014; 38: 296-308. 
[27] S.S. Chandel, P. Ramasamy, K.S.R Murthy. Wind power potential assessment of 12 locations in western Himalayan region of India. Renewable and Sustainable Energy Reviews 2014; 39: 530-545.

[28] Inci Türk Togrul, Meerim Imas Kizi. Determination of wind energy potential and wind speed data in Bishkek, Kyrgyzstan. International Journal of Green Energy 2008; 5: 157-173.

[29] Shahnawaz Farhan Khahro, Kavita Tabbassum, Amir Mahmood Soomro, Xiaozhong Liao, Muhammad Bux Alvi, Lei Dong, M. Farhan Manzoor. Technoeconomical evaluation of wind energy potential and analysis of power generation from wind at Gharo, Sindh Pakistan. Renewable and Sustainable Energy Reviews 2014; 35: 460-474.

[30] Sultan AL-Yahyai, Yassine Charabi, Adel Gastli, Saleh Al-Alawi. Assessment of wind energy potential locations in Oman using data from existing weather stations. Renewable and Sustainable Energy Reviews 2010; 14: 1428-1436.

[31] Cumali Ikilic. Wind energy and assessment of wind energy potential in Turkey. Renewable and Sustainable Energy Reviews 2012; 16: 1165- 1173.

[32] Y. Himri, S. Rehman, B. Draoui, S. Himri. Wind power potential assessment for three locations in Algeria. Renewable and Sustainable Energy Reviews 2008; 12: 2495-2504.

[33] P. Alamdari, O. Nematollahi, M. Mirhosseini. Assessment of wind energy in Iran: A review. Renewable and Sustainable Energy Reviews 2012; 16: 836- 860.

[34] Ahmed Shata Ahmed. Potential wind power generation in South Egypt. Renewable and Sustainable Energy Reviews 2012; 16: 1528- 1536.

[35] Olayinka S. Ohunakin. Assessment of wind energy resources for electricity generation using WECS in North-Central region, Nigeria. Renewable and Sustainable Energy Reviews 2011; 15: 1968-1976.

[36] Kostas Philippopoulos, Despina Deligiorgi, George Karvounis. Wind speed distribution modeling in the greater area of chania, Greece. International Journal of Green Energy 2012; 9: 174-193. 
[37] Q. Hernández-Escobedo, R. Saldaña-Flores, E.R. Rodríguez-García, F. ManzanoAgugliaro. Wind energy resource in Northern Mexico. Renewable and Sustainable Energy Reviews 2014; 32: 890-914.

[38] Brian W. Raichle, W. Richard Carson. Wind resource assessment of the Southern Appalachian Ridges in the Southeastern United States. Renewable and Sustainable Energy Reviews 2009; 13: 1104-1110.

[39] Francisco González-Longatt, Javier Serrano González, Manuel Burgos Payán, Jesús Manuel Riqueme Santos. Wind-resource atlas of Venezuela based on on-site anemometry observation. Renewable and Sustainable Energy Reviews 2014; 39: 898-911.

[40] F.C. Odo, S.U. Offiah and P.E. Ugwuoke. Weibull distribution-based model for prediction of wind potential in Enugu, Nigeria. Advances in Applied Science Research 2012; 3 (2): 1202-1208.

[41] Windographer 3.2.3, 2014. Wind Resources Assessment Tool. http://www.mitsaya.com. 
Fig. 1. Regional distribution of global Installed wind power capacity. Data source: [3].................1

Fig. 2. Weather stations at Jubail industrial city ..................................................................... 2

Fig. 3. Wind speed statistics of all weather stations at Jubail at $10 \mathrm{~m}$ AGL. .................................. 3

Fig. 4. Wind rose plot at $10 \mathrm{~m}$ height...................................................................................... 3

Fig. 5. Wind rose plot at $50 \mathrm{~m}$ height.................................................................................... 4

Fig. 6. Wind rose plot at $90 \mathrm{~m}$ height..................................................................................... 4

Fig. 7. Annual variation of hourly mean wind speed at different heights..................................... 5

Fig. 8. Seasonal variation of hourly mean wind speed at different heights.................................... 5

Fig. 9. Diurnal variation of hourly mean wind speed at different heights. ................................... 6

Fig. 10. Actual wind speed frequency distribution and Weibull fit at $10 \mathrm{~m}$ AGL. ........................ 6

Fig. 11. Actual wind speed frequency distribution and Weibull fit at $50 \mathrm{~m}$ AGL. ........................ 7

Fig. 12. Actual wind speed frequency distribution and Weibull fit at $90 \mathrm{~m}$ AGL. ........................ 7

Fig. 13. Seasonal air density variation at Jubail. ...................................................................... 8

Fig. 14. Variation of mean annual wind power density per unit. ................................................... 8

Fig. 15. Variation of mean seasonal wind power density per unit area.......................................... 9

Fig. 16. Variation of mean diurnal wind power density per unit area. .......................................... 9

Fig. 17. Variation of wind speed with height and fitting curve. .................................................. 10

Fig. 18. Variation of mean annual wind shear at different height. .............................................. 10

Fig. 19. Variation of mean diurnal wind shear at different heights.............................................. 11

Fig. 20. Variation of mean diurnal wind shear at different heights............................................. 11

Fig. 21. Power curves of the selected wind machines.................................................................... 12

Fig. 22. Comparison of the seasonal energy output from the selected wind machines. ................ 12

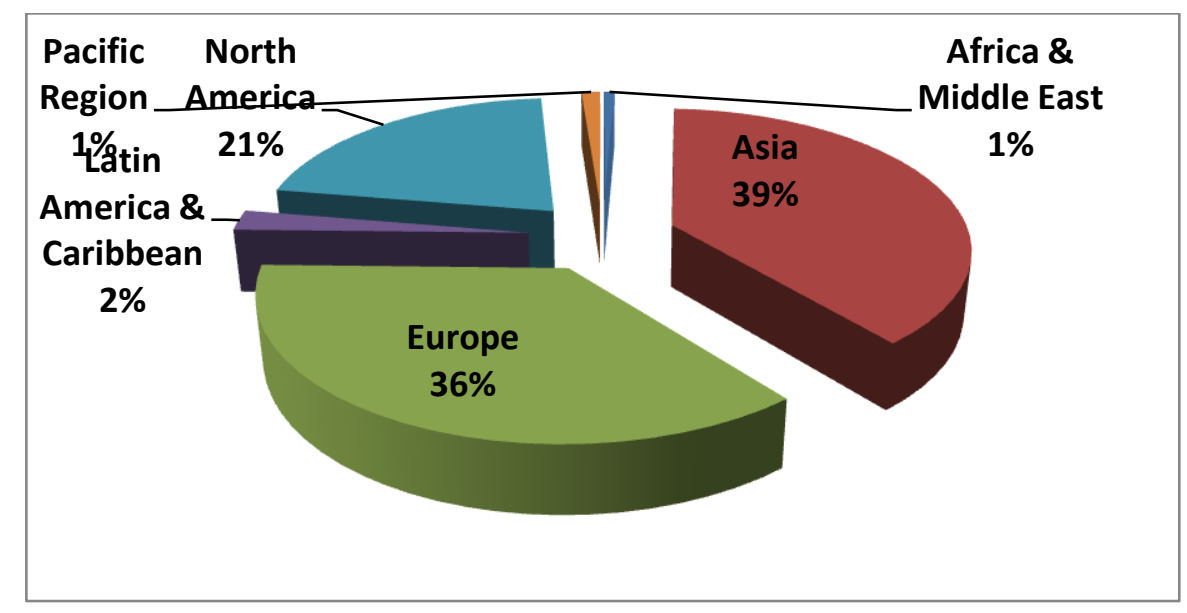

Fig. 1. Regional distribution of global Installed wind power capacity. Data source: [3] 


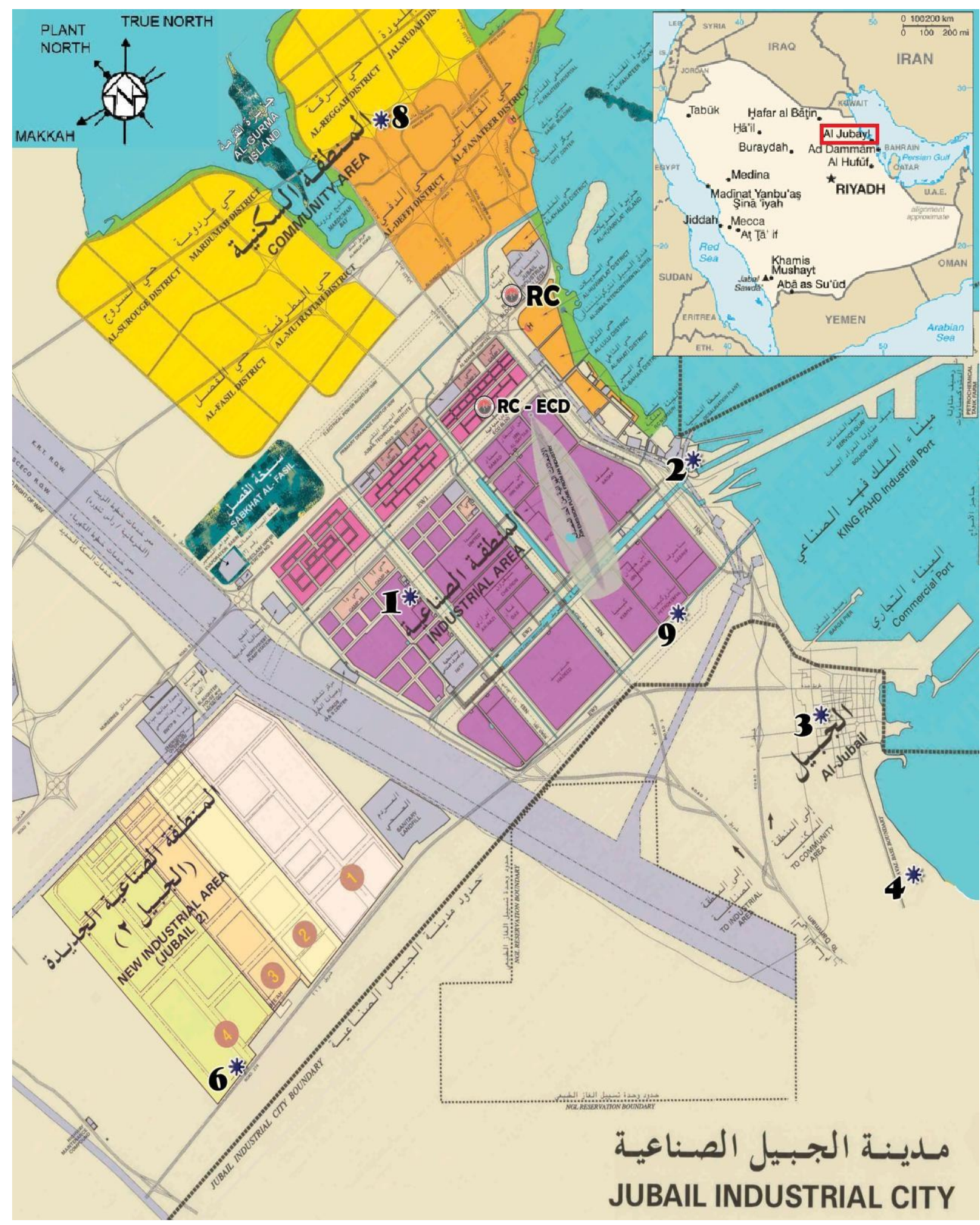

Fig. 2. Weather stations at Jubail industrial city 


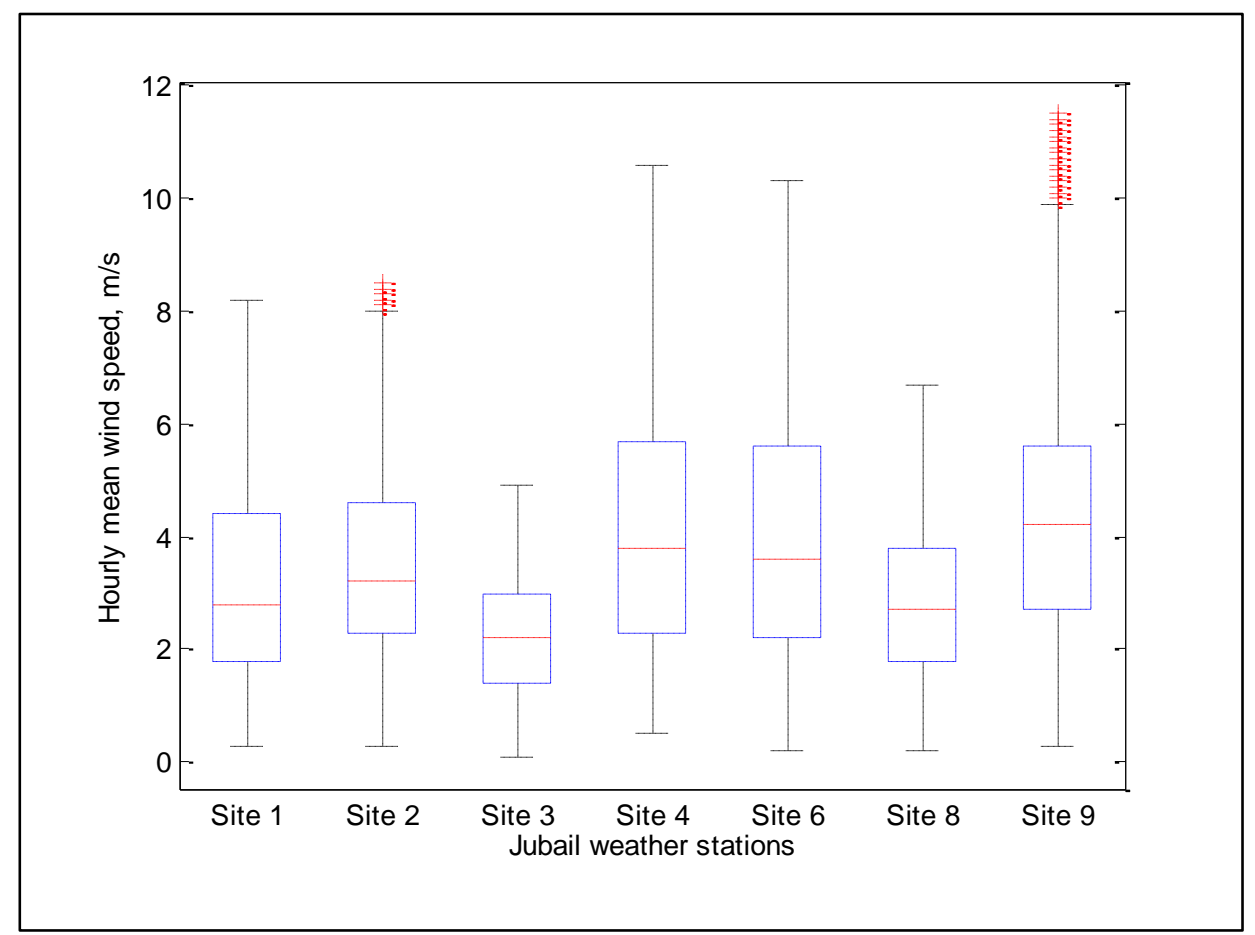

Fig. 3. Wind speed statistics of all weather stations at Jubail at $10 \mathrm{~m}$ AGL.

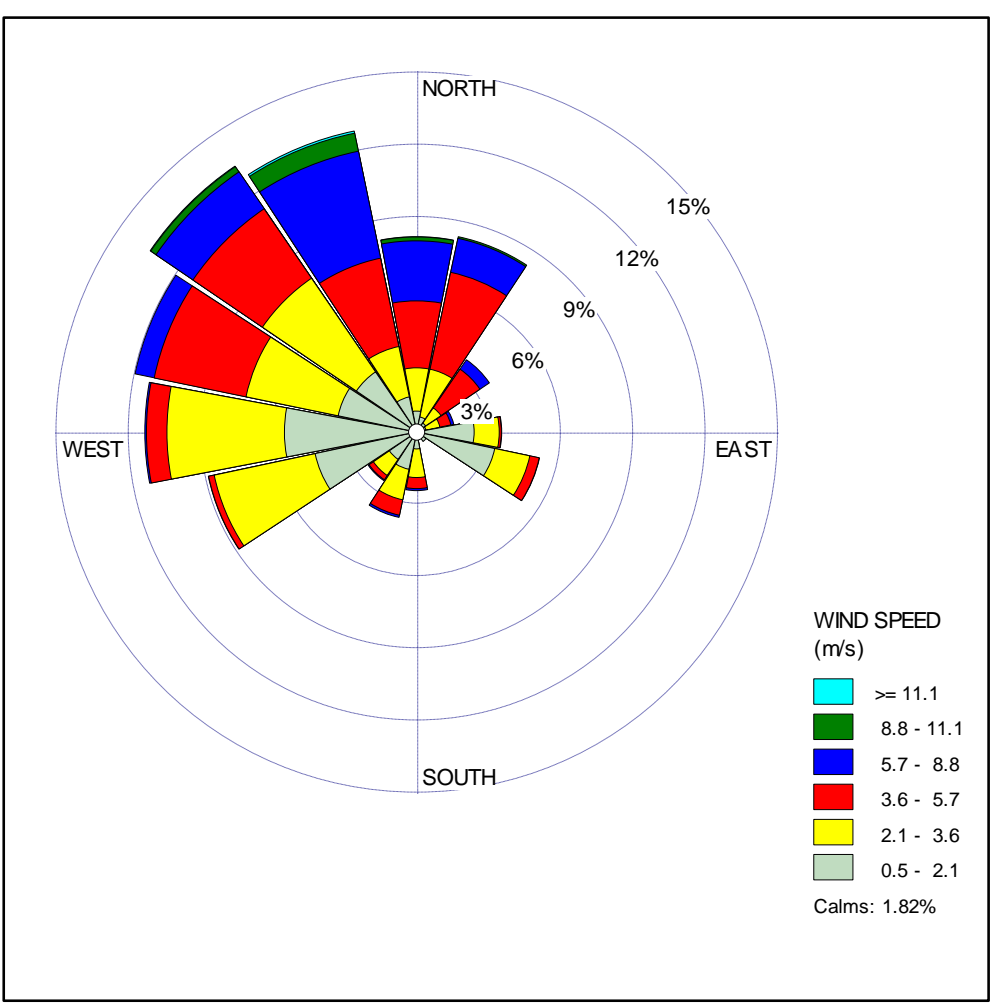

Fig. 4. Wind rose plot at $10 \mathrm{~m}$ height. 


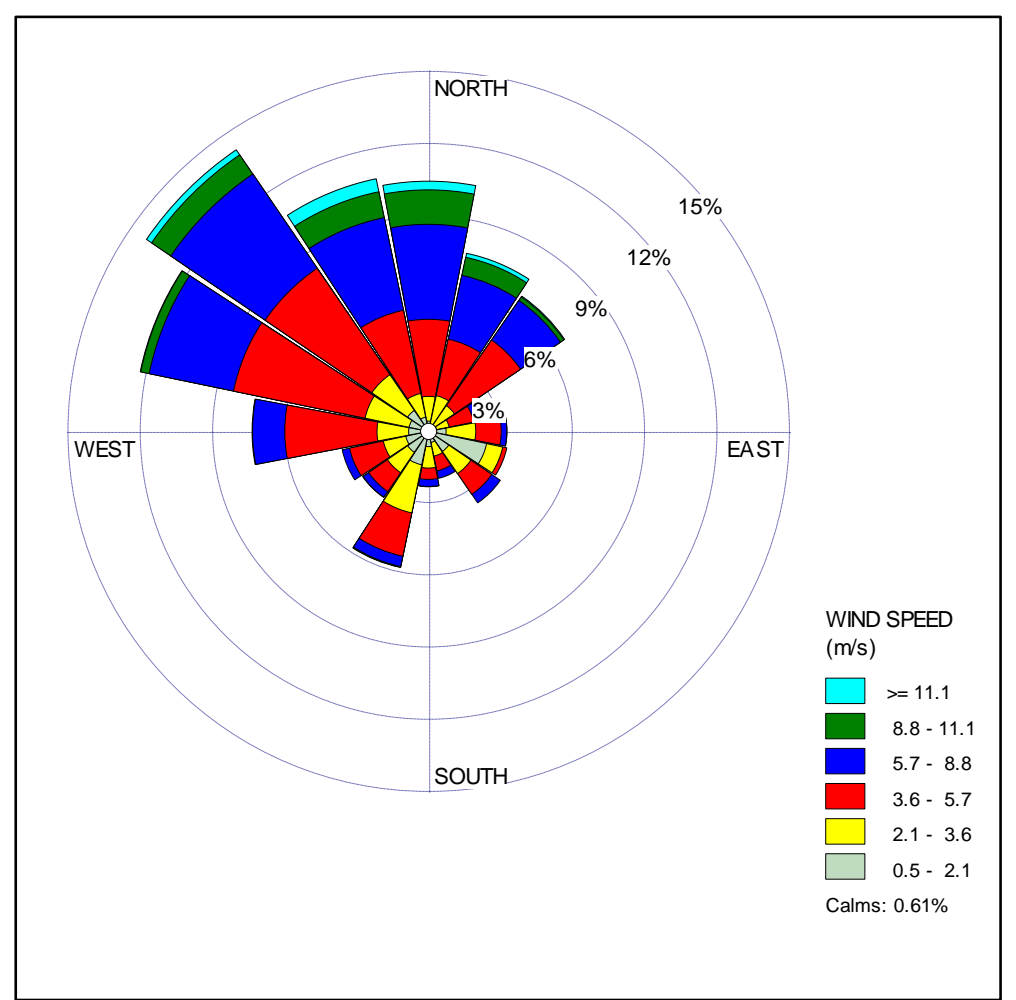

Fig. 5. Wind rose plot at $50 \mathrm{~m}$ height.

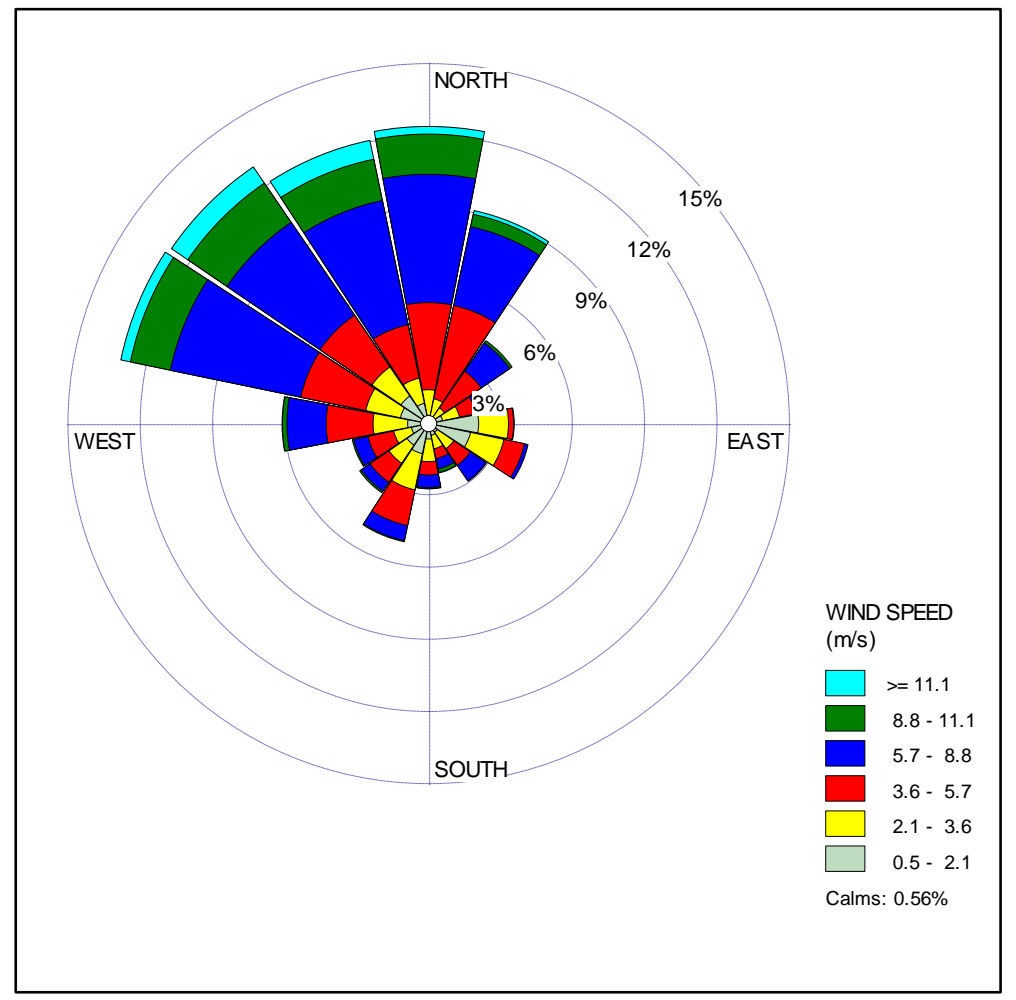

Fig. 6. Wind rose plot at $90 \mathrm{~m}$ height. 


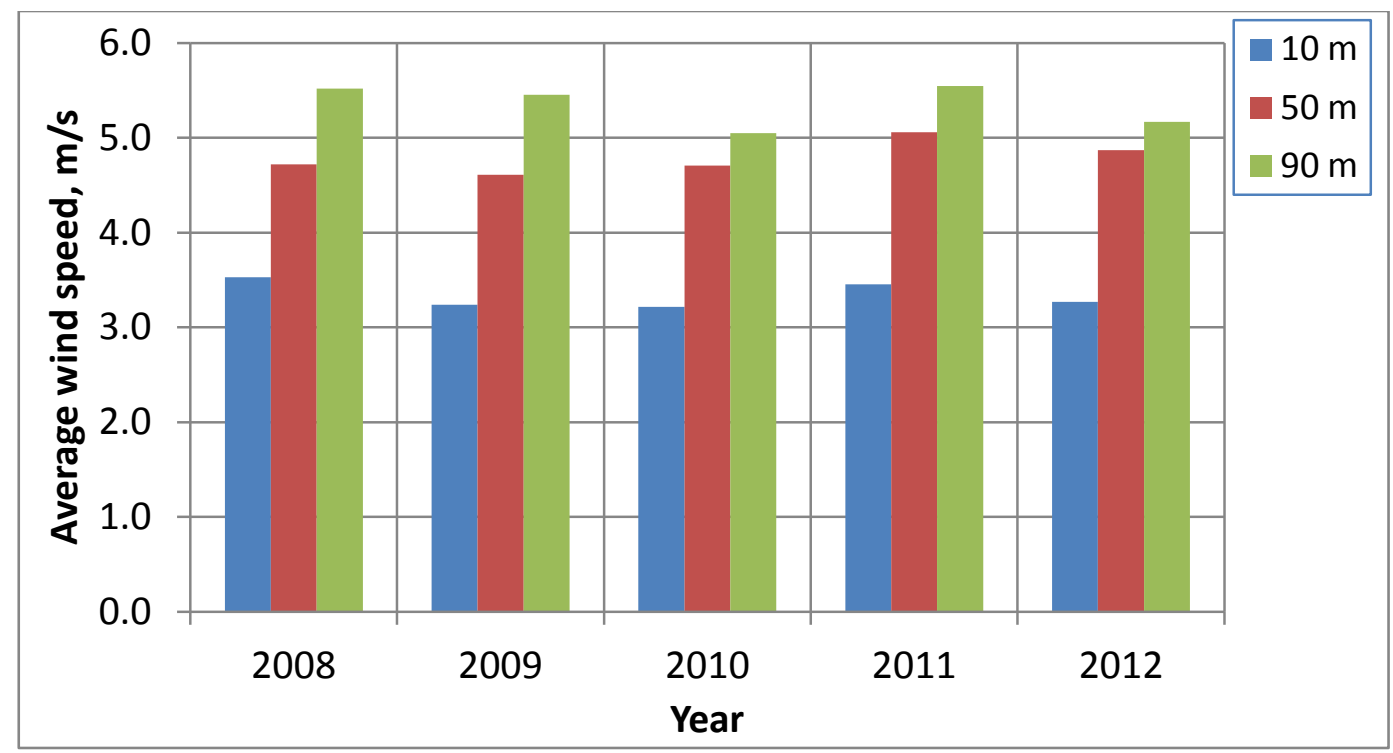

Fig. 7. Annual variation of hourly mean wind speed at different heights.

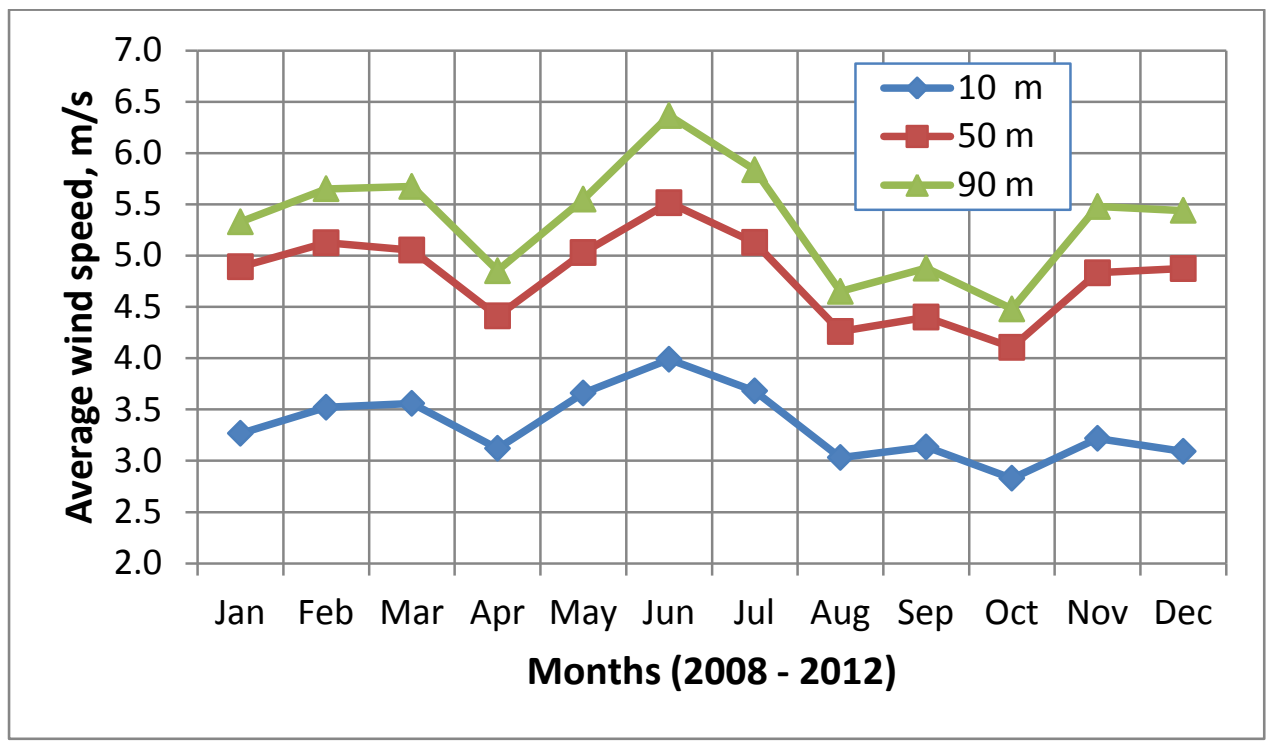

Fig. 8. Seasonal variation of hourly mean wind speed at different heights. 


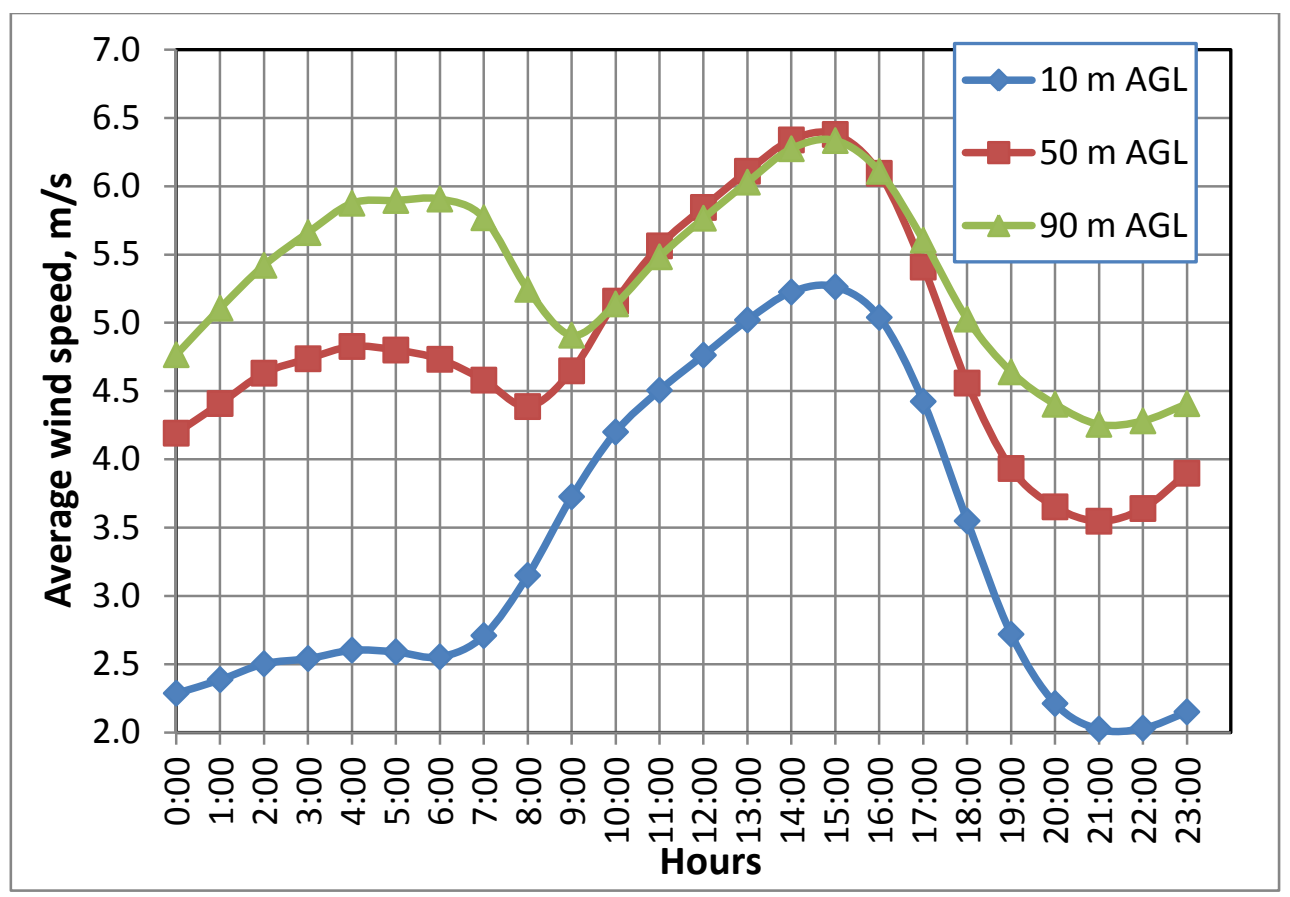

Fig. 9. Diurnal variation of hourly mean wind speed at different heights.

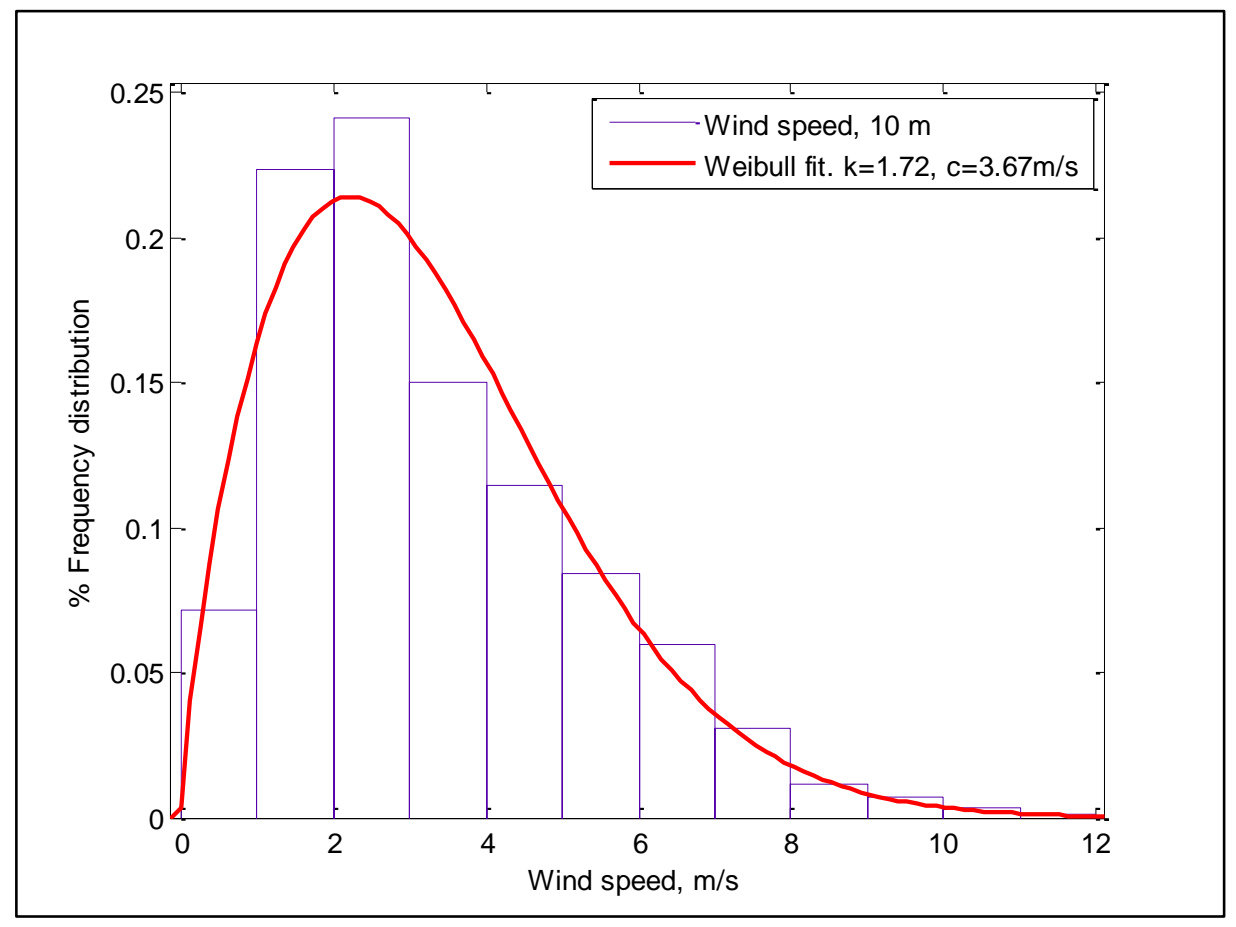

Fig. 10. Actual wind speed frequency distribution and Weibull fit at $10 \mathrm{~m}$ AGL. 


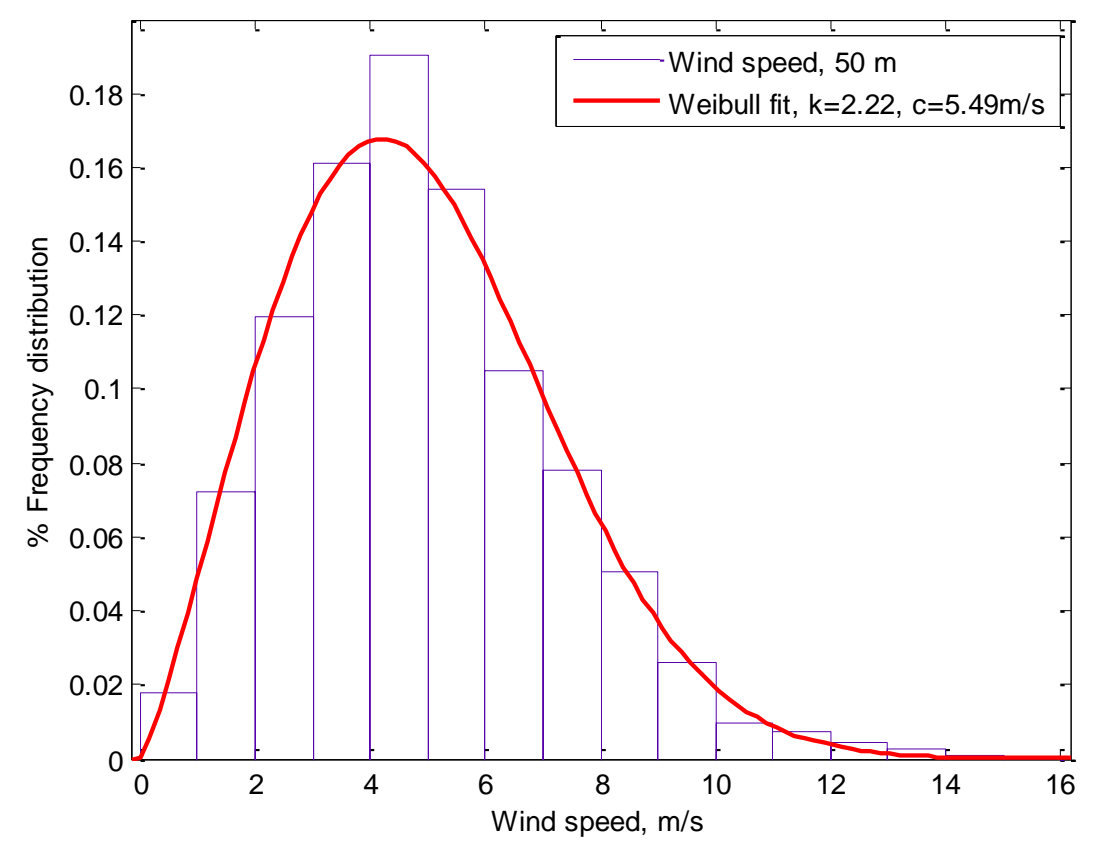

Fig. 11. Actual wind speed frequency distribution and Weibull fit at $50 \mathrm{~m}$ AGL.

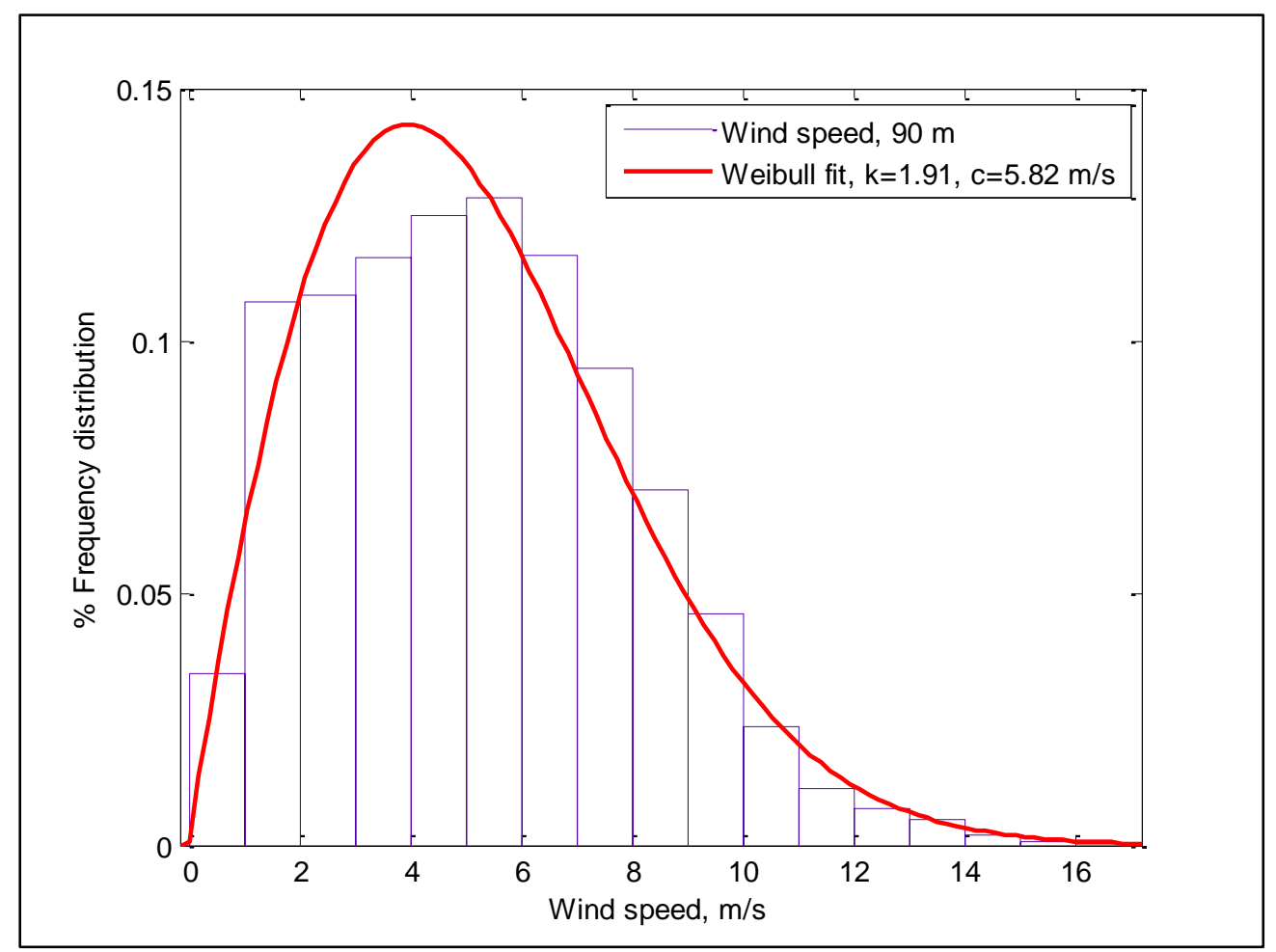

Fig. 12. Actual wind speed frequency distribution and Weibull fit at $90 \mathrm{~m}$ AGL. 


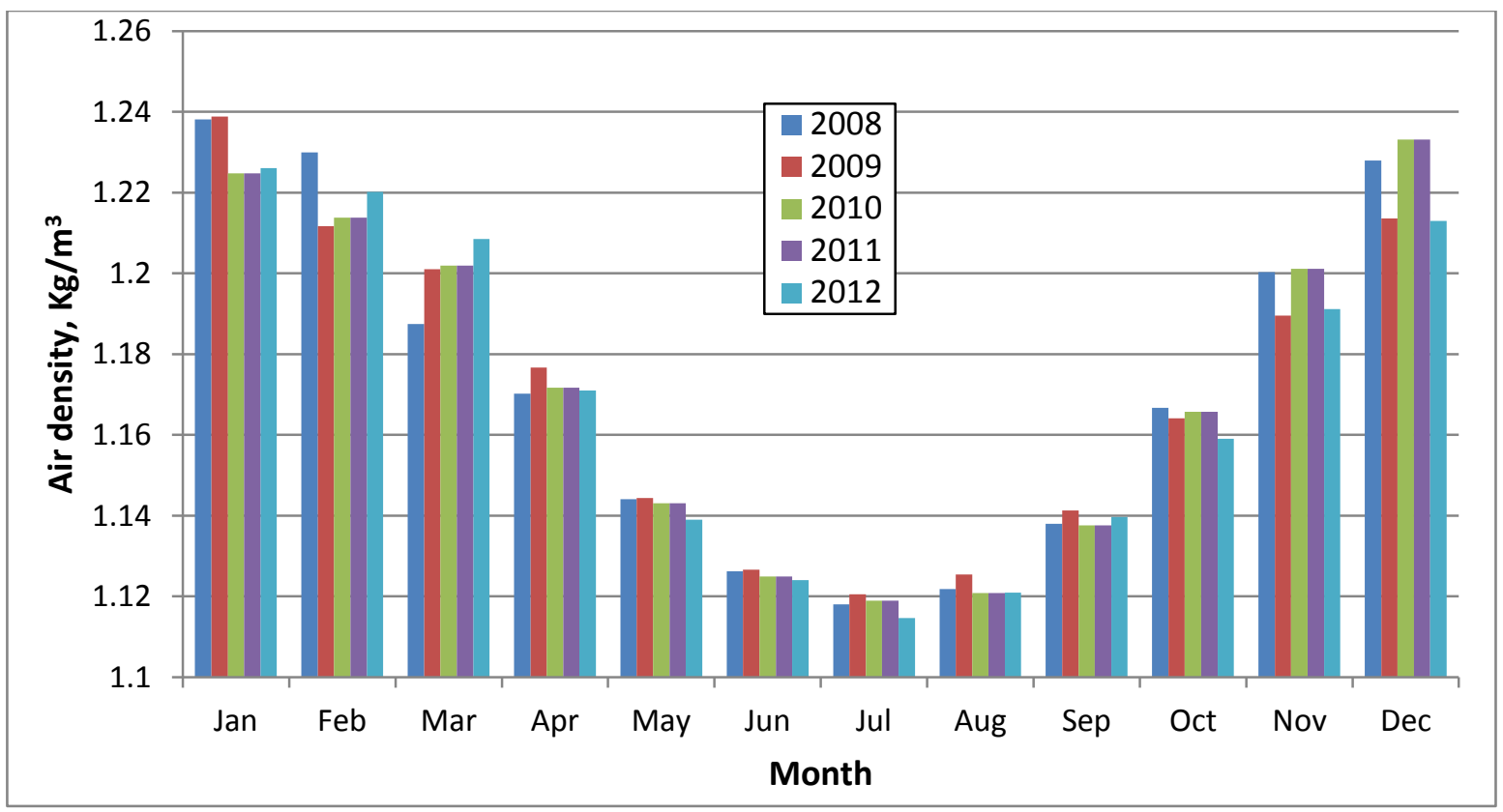

Fig. 13. Seasonal air density variation at Jubail.

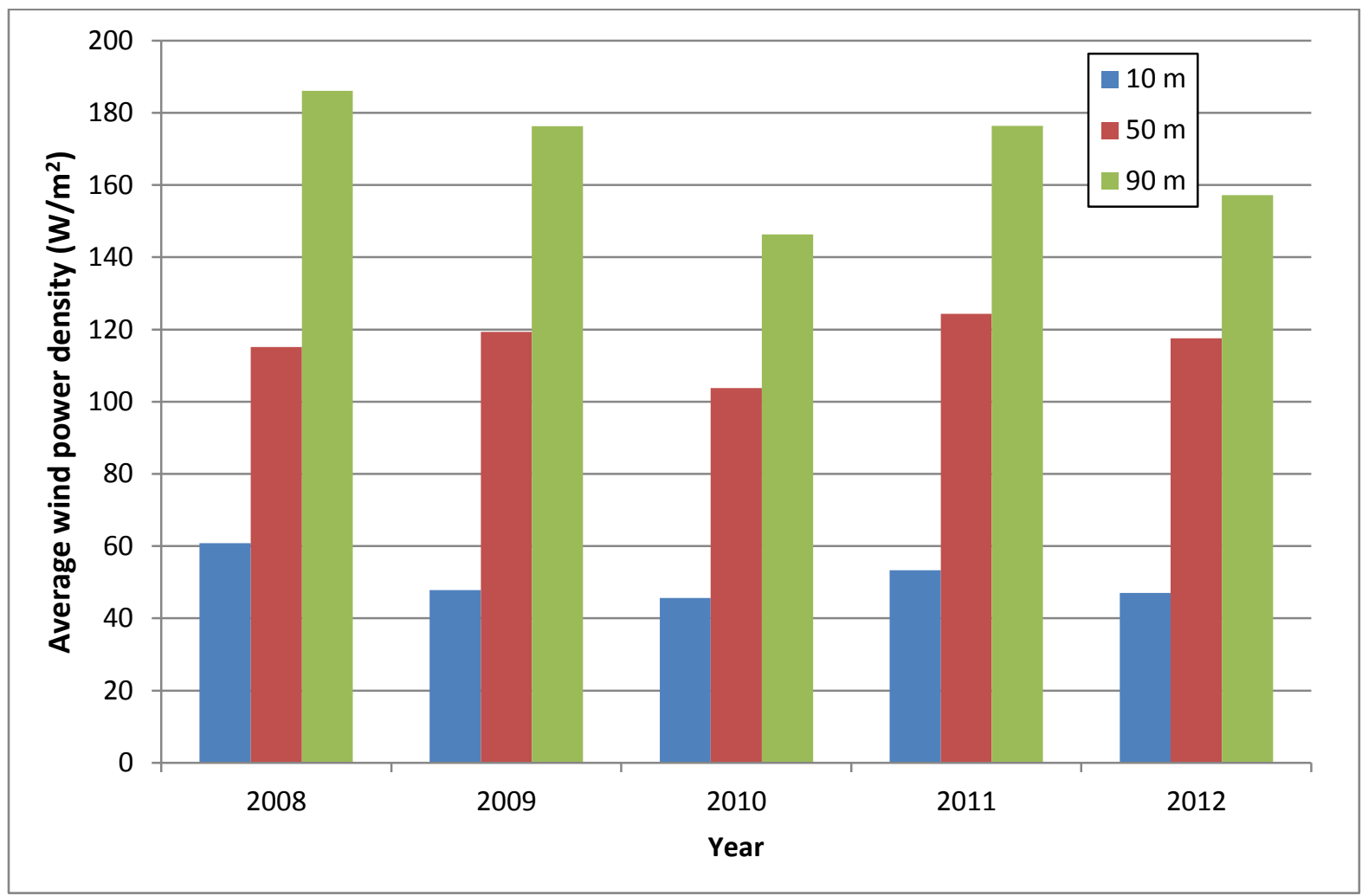

Fig. 14. Variation of mean annual wind power density per unit. 


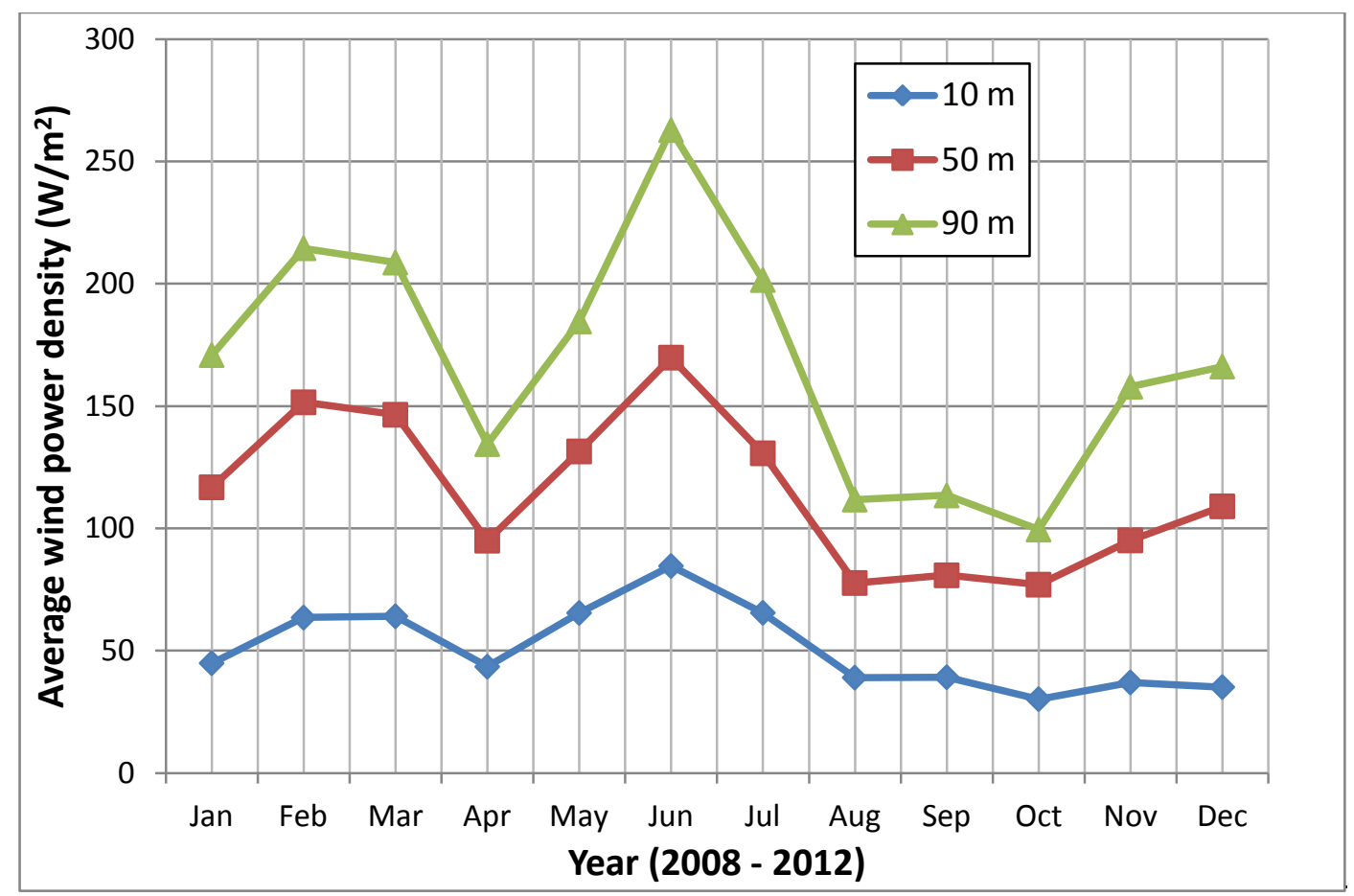

Fig. 15. Variation of mean seasonal wind power density per unit area.

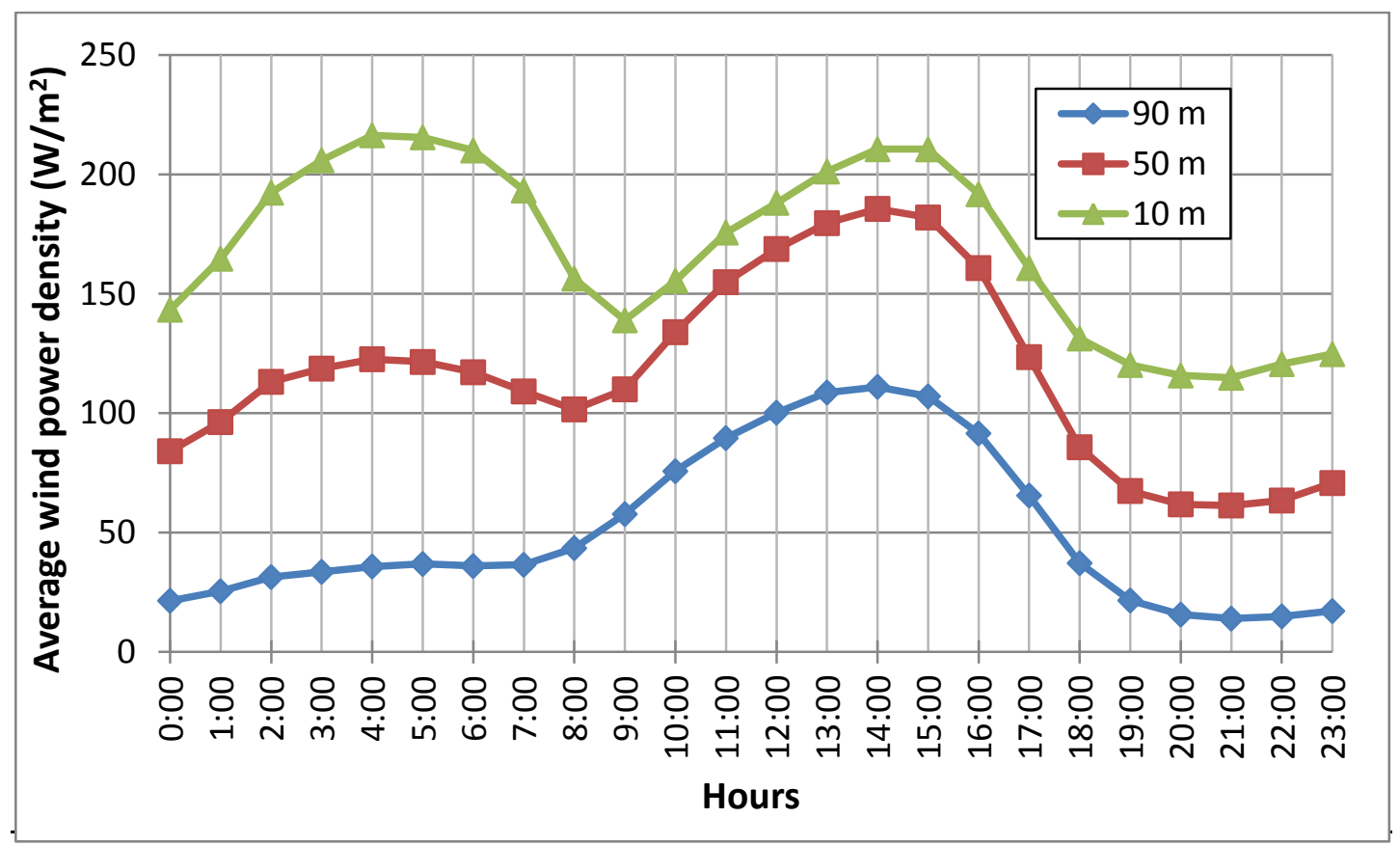

Fig. 16. Variation of mean diurnal wind power density per unit area. 


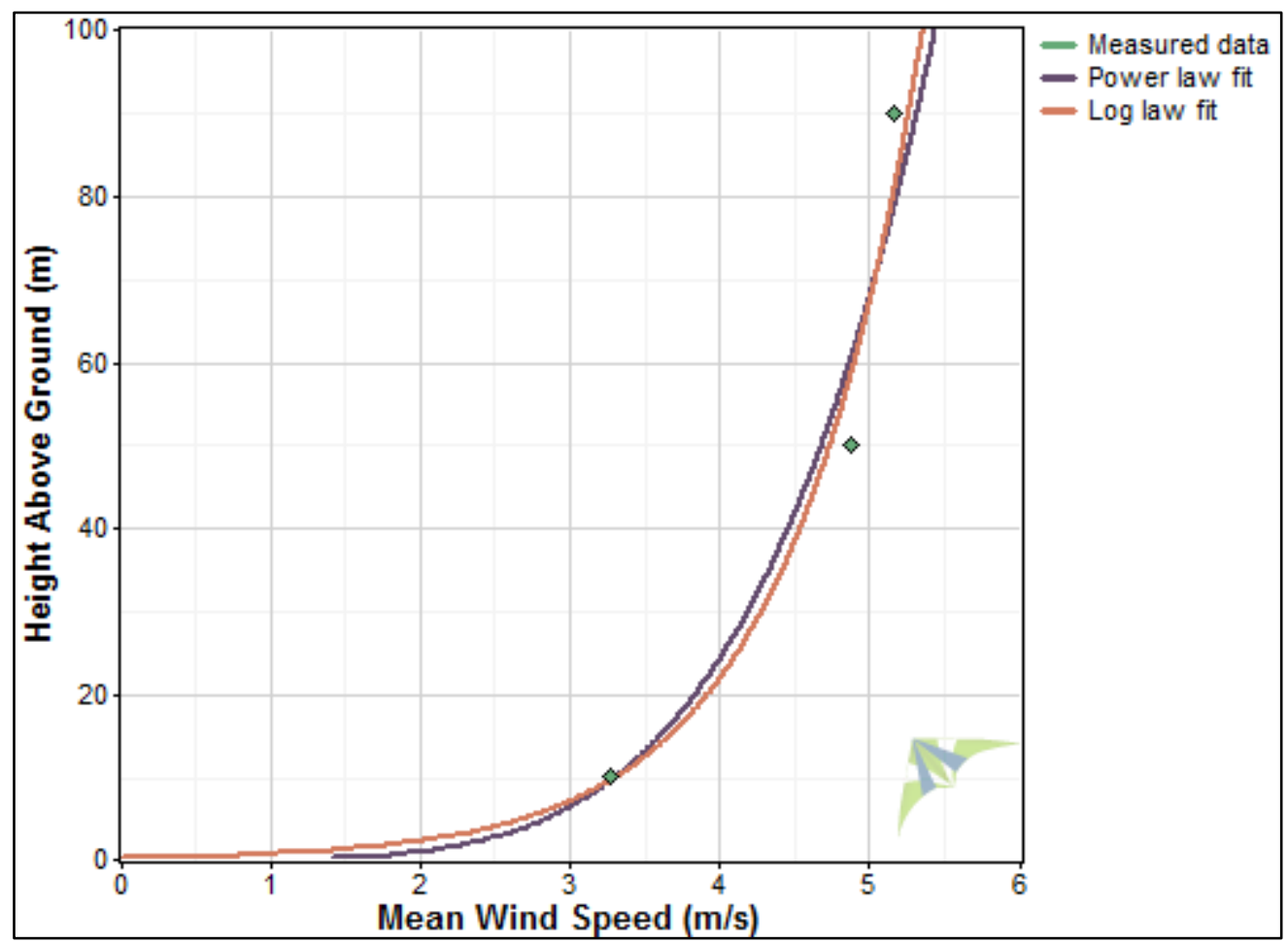

Fig. 17. Variation of wind speed with height and fitting curve.

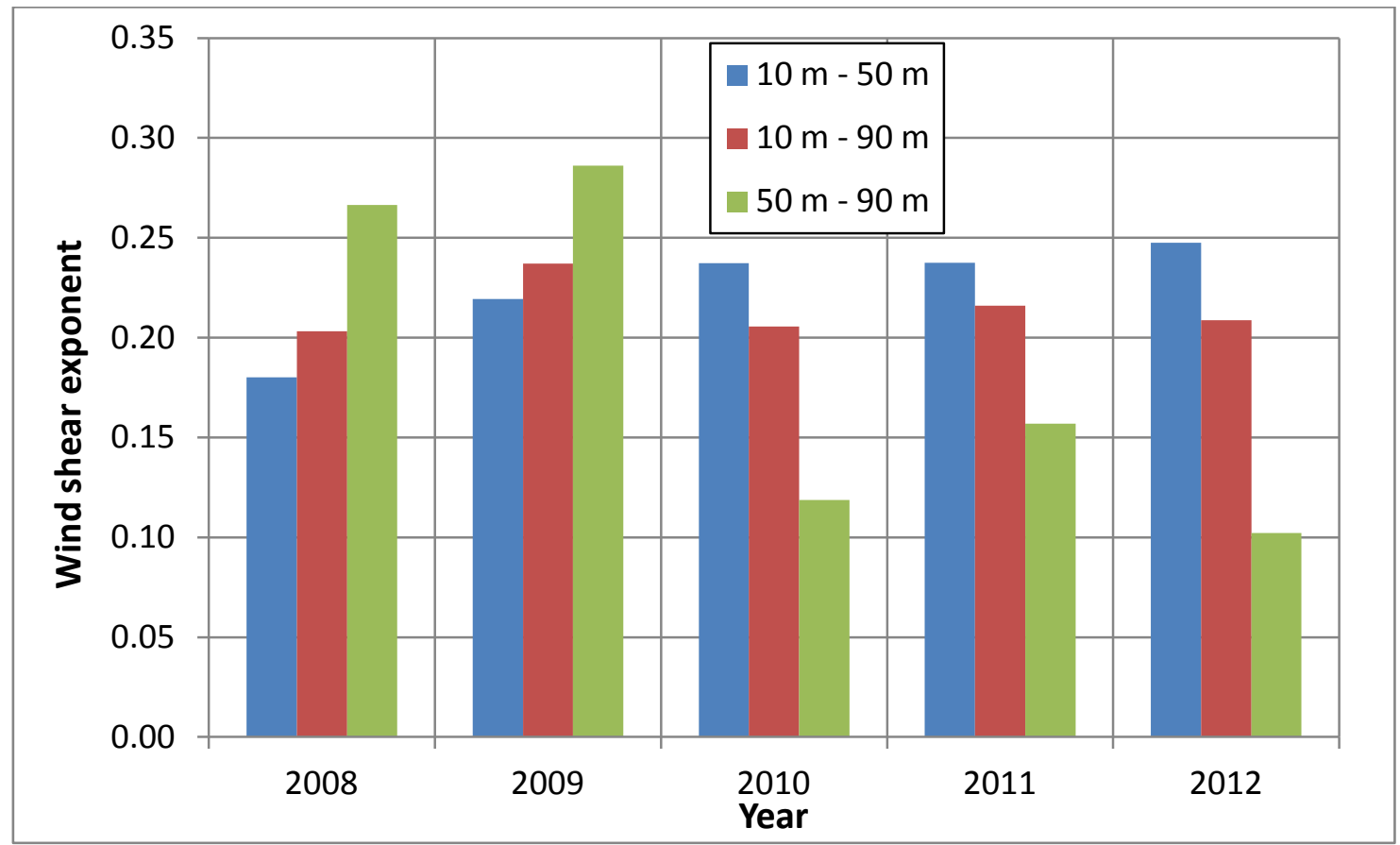

Fig. 18. Variation of mean annual wind shear at different height. 


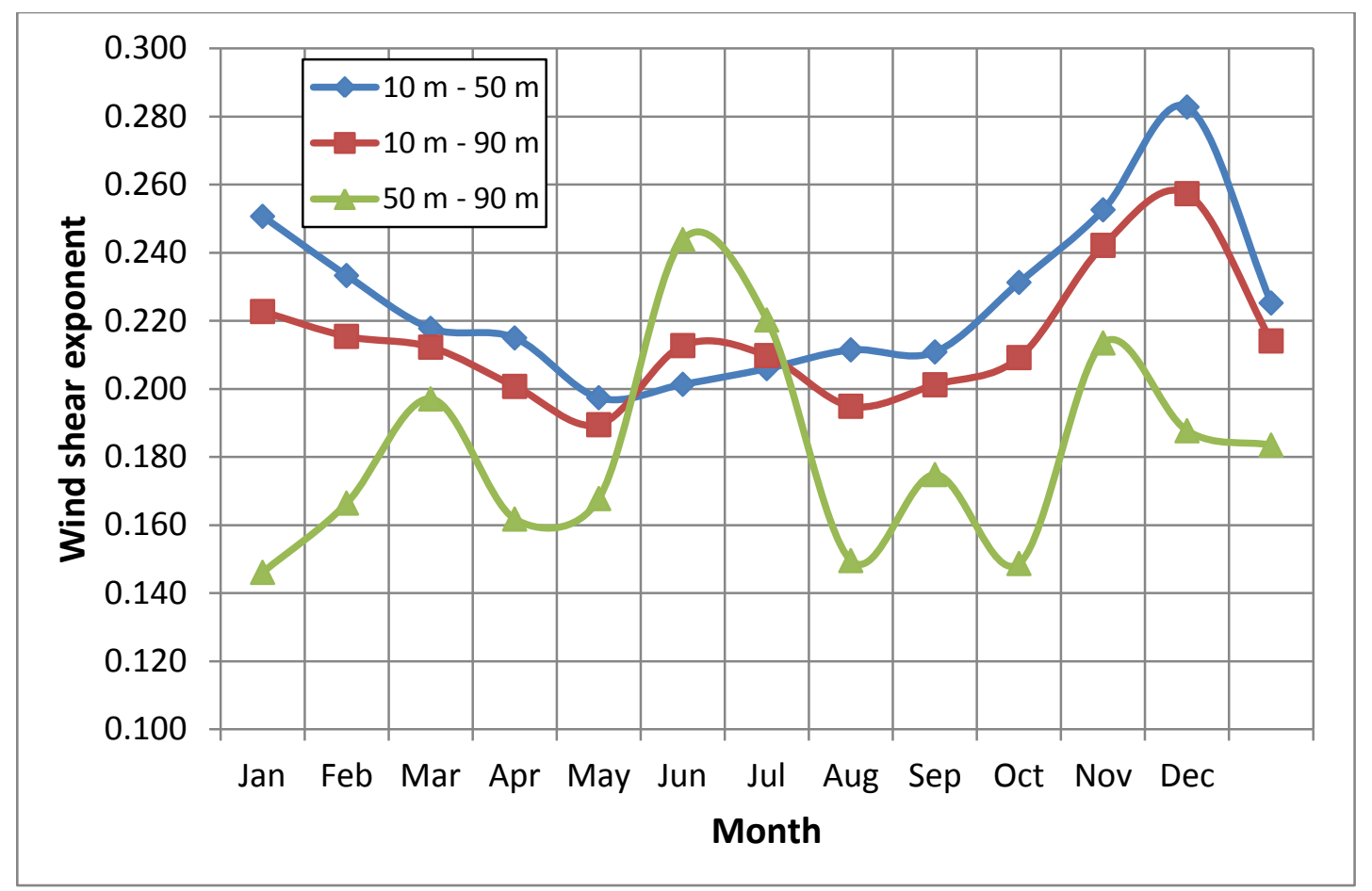

Fig. 19. Variation of mean diurnal wind shear at different heights.

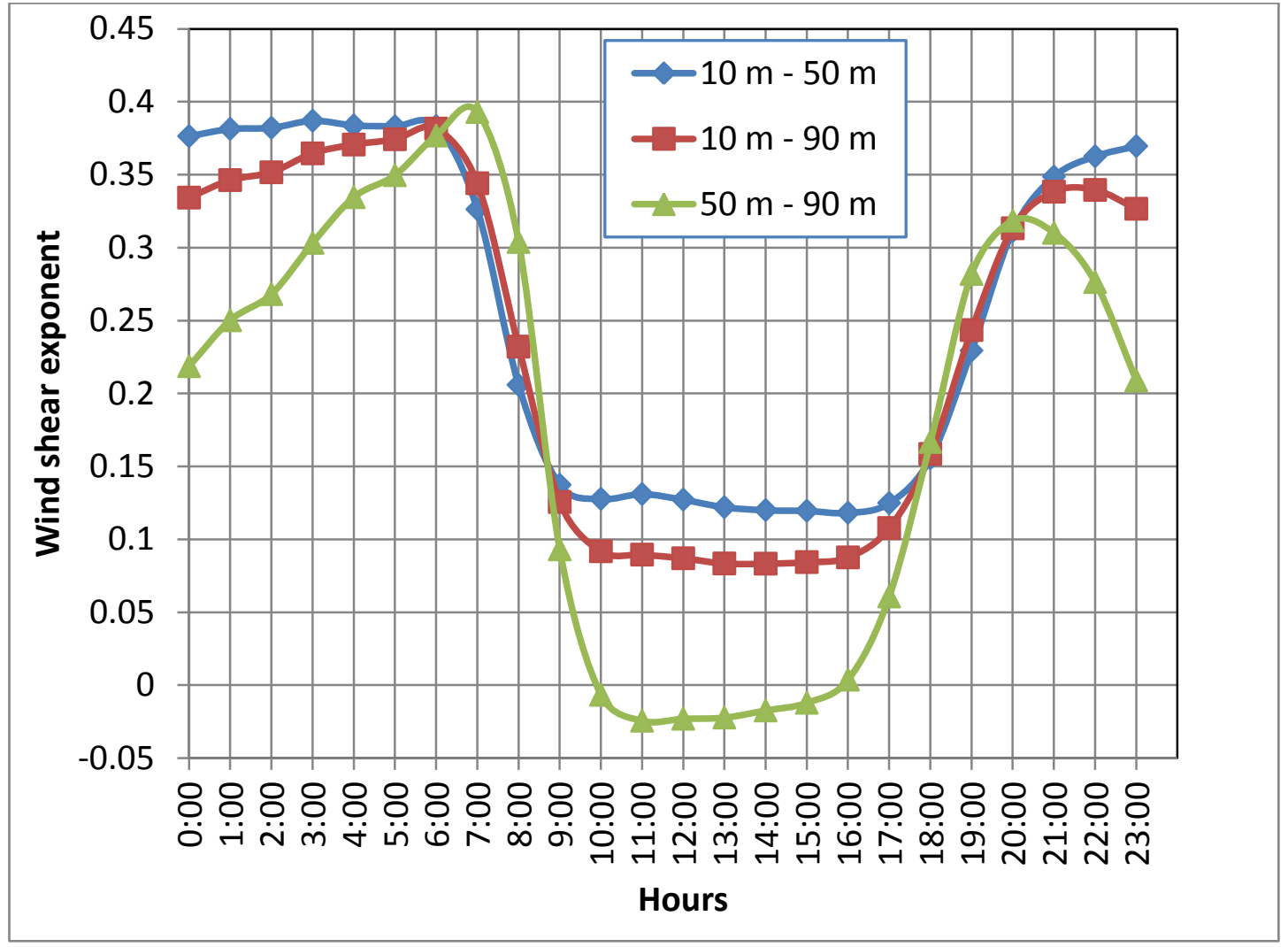

Fig. 20. Variation of mean diurnal wind shear at different heights. 


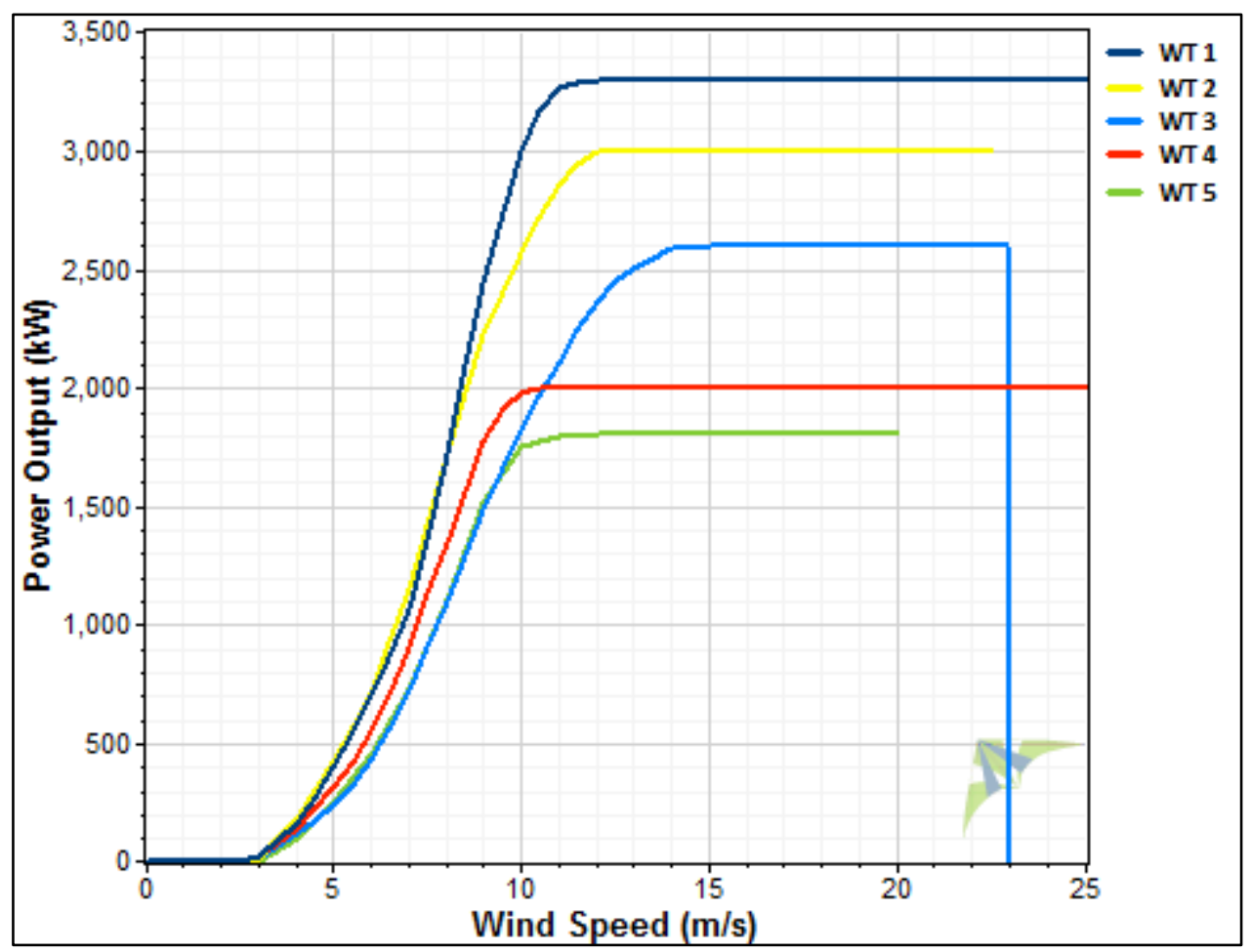

Fig. 21. Power curves of the selected wind machines.

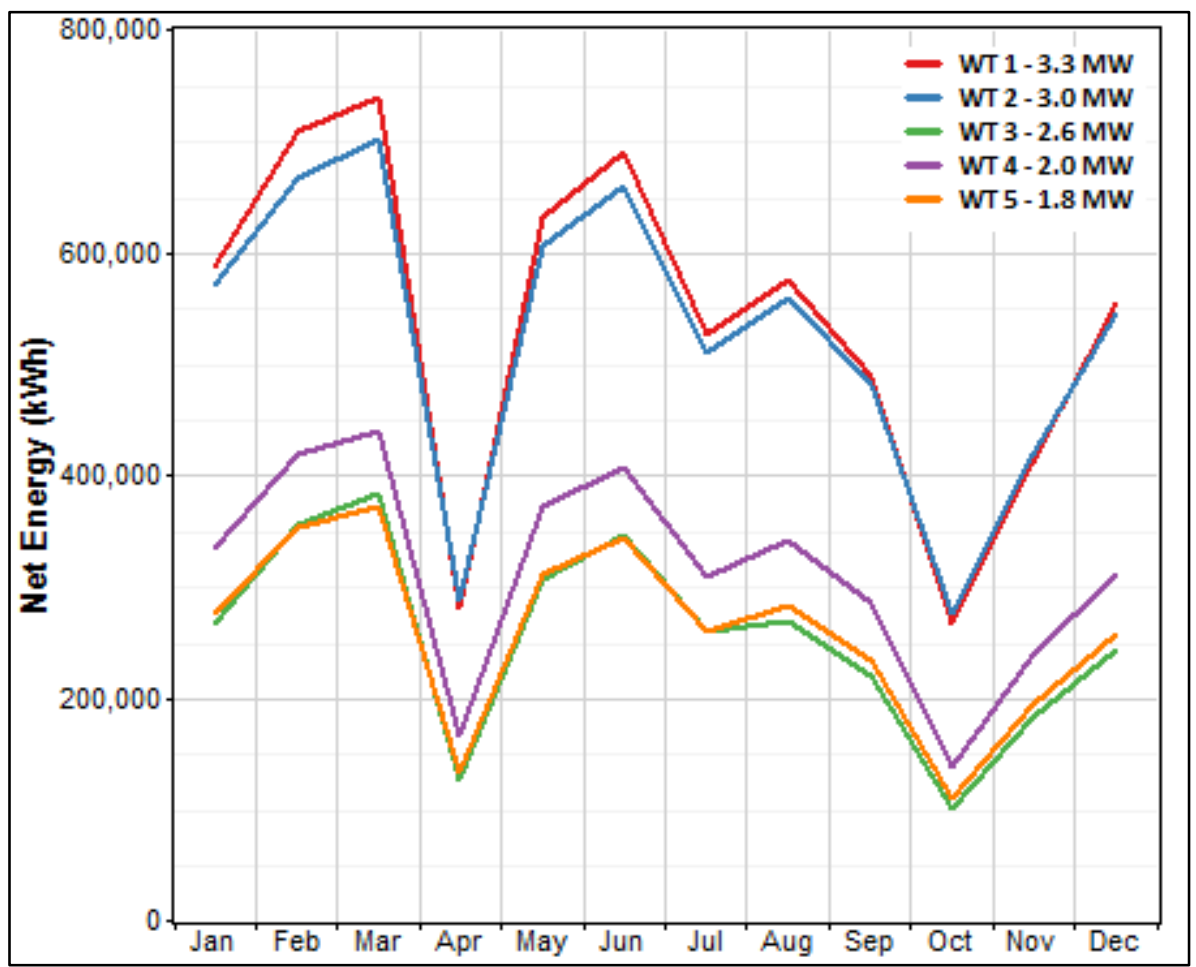

Fig. 22. Comparison of the seasonal energy output from the selected wind machines. 


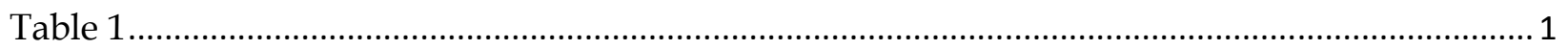

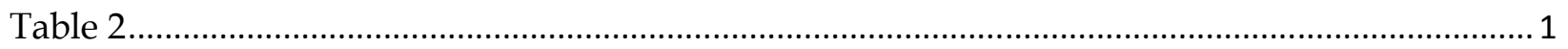

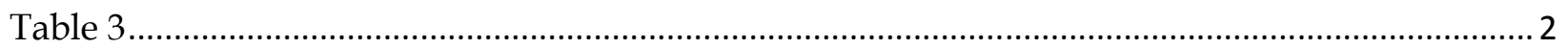

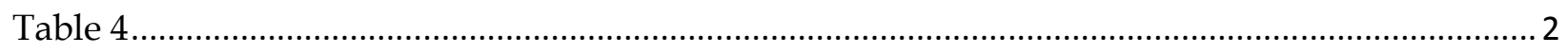

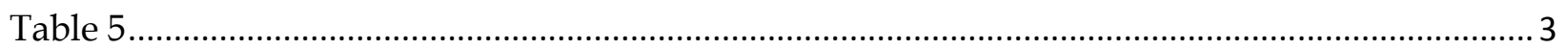

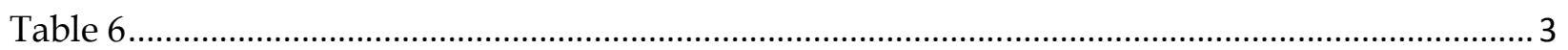

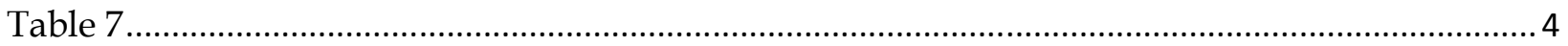

Table 1

Latitude/Longitude and UTM Coordinates of weather data collection sites in Jubail.

\begin{tabular}{cccc}
\hline & & Degrees, Minutes, Seconds & UTM \\
\hline \multirow{2}{*}{ Site01 } & Latitude & $27^{\circ} 2^{\prime} 15.76^{\prime \prime} \mathrm{N}$ & $2,991,457.88$ \\
& Longitude & $49^{\circ} 32^{\prime} 2.56^{\prime \prime} \mathrm{E}$ & $354,594.12$ \\
\multirow{2}{*}{ Site02 } & Latitude & $27^{\circ} 4^{\prime} 27.49^{\prime \prime} \mathrm{N}$ & $2,995,436.09$ \\
& Longitude & $4^{\circ} 36^{\prime} 3.24^{\prime \prime} \mathrm{E}$ & $361,271.25$ \\
\multirow{2}{*}{ Site03 } & Latitude & $27^{\circ} 0^{\prime} 36.85^{\prime \prime} \mathrm{N}$ & $2,988,282.92$ \\
& Longitude & $4^{\circ} 39^{\prime} 9.56^{\prime \prime} \mathrm{E}$ & $366,327.78$ \\
\multirow{2}{*}{ Site04 } & Latitude & $26^{\circ} 55^{\prime} 39.92^{\prime \prime} \mathrm{N}$ & $2,979,084.69$ \\
& Longitude & $49^{\circ} 42^{\prime} 42.89^{\prime \prime} \mathrm{E}$ & $372,114.33$ \\
\multirow{2}{*}{ Site06 } & Latitude & $26^{\circ} 55^{\prime} 13.40^{\prime \prime} \mathrm{N}$ & $2,978,520.20$ \\
& Longitude & $4^{\circ} 29^{\prime} 0.10^{\prime \prime} \mathrm{E}$ & $349,410.12$ \\
\multirow{2}{*}{ Site08 } & Latitude & $27^{\circ} 7^{\prime} 54.03^{\prime \prime} \mathrm{N}$ & $3,001,869.16$ \\
& Longitude & $49^{\circ} 31^{\prime} 57.02^{\prime \prime} \mathrm{E}$ & $354,562.88$ \\
\multirow{2}{*}{ Site09 } & Latitude & $27^{\circ} 1^{\prime} 49.95^{\prime \prime} \mathrm{N}$ & $2,990,576.71$ \\
& Longitude & $49^{\circ} 36^{\prime} 41.14 " \mathrm{E}$ & $362,261.81$ \\
\hline
\end{tabular}

Table 2

Specifications of the wind speed sensor at data collection site.

\begin{tabular}{ll}
\hline Performance Characteristics & \\
\hline Manufacturer: & Met One Instruments, \\
Maximum Operating Range: & Inc. $0-60 \mathrm{~m} / \mathrm{s}$ \\
Starting Speed: & $0.22 \mathrm{~m} / \mathrm{s}$ \\
Calibrated Range: & $0-50 \mathrm{~m} / \mathrm{s}$ \\
Accuracy: & $\pm 1 \%$ or $0.07 \mathrm{~m} / \mathrm{s}$ \\
Resolution: & $<0.1 \mathrm{~m} / \mathrm{s}$ \\
Temperature Range: & $-50^{\circ} \mathrm{C}$ to $+65^{\circ} \mathrm{C}$ \\
Distance Constant: & less than $1.5 \mathrm{~m}$ of flow \\
\hline
\end{tabular}


Table 3

Parameter list of the weather data collection tower.

\begin{tabular}{lrl}
\hline Parameter Code & Description & Unit \\
\hline ATM & Ambient Temperature & ${ }^{\circ} \mathrm{C}$ \\
PRE & Precipitation Pressure & $\mathrm{mm}$ \\
PRS & Relative Humidity & $\mathrm{mb}$ \\
RH & Global Solar & $\%$ \\
GSR & Radiation Wind & Langley \\
VWD10 & Direction 10m Wind & $\mathrm{deg}$ \\
VWD50 & Direction 50m Wind & $\mathrm{deg}$ \\
VWD90 & Direction 90m Wind & $\mathrm{deg}$ \\
VWS10 & Speed 10m Wind & $\mathrm{m} / \mathrm{s}$ \\
VWS50 & Speed 50m Wind & $\mathrm{m} / \mathrm{s}$ \\
VWS90 & Speed 90m & $\mathrm{m} / \mathrm{s}$ \\
\hline
\end{tabular}

Table 4

Metrological data at the weather data collection tower.

\begin{tabular}{|c|c|c|c|}
\hline \multicolumn{4}{|c|}{ Monthly Average (2008 - 2012) } \\
\hline & Temperature & Atmospheric & Relative \\
\hline Jan & 15.28 & 1017.9 & 63.12 \\
\hline $\mathrm{Feb}$ & 17.42 & 1015.5 & 58.62 \\
\hline Mar & 21.05 & 1013.2 & 47.05 \\
\hline Apr & 26.06 & 1009.2 & 45.03 \\
\hline May & 32.16 & 1004.9 & 36.88 \\
\hline June & 35.71 & 999.5 & 27.98 \\
\hline July & 36.77 & 996.3 & 32.96 \\
\hline Aug & 36.14 & 998.0 & 43.69 \\
\hline Sep & 33.56 & 1003.6 & 45.59 \\
\hline Oct & 29.15 & 1010.3 & 54.04 \\
\hline Nov & 22.68 & 1014.8 & 58.64 \\
\hline Dec & 17.19 & 1017.5 & 60.58 \\
\hline Mean & 26.93 & 1008.4 & 47.85 \\
\hline
\end{tabular}


Table 5

Weibull shape and scale parameters for Jubail.

\begin{tabular}{ccccccc}
\hline Month & \multicolumn{1}{c}{ 10 $\mathbf{~ m}$ AGL } & \multicolumn{2}{c}{$\mathbf{5 0} \mathbf{m}$ AGL } & \multicolumn{2}{c}{ 90 $\mathbf{m}$ AGL } \\
& $\mathbf{k}$ & $\mathbf{c}$ & $\mathbf{K}$ & $\mathbf{c}$ & $\mathbf{K}$ & $\mathbf{c}$ \\
\hline Jan & 1.92 & 3.58 & 2.64 & 5.76 & 2.00 & 5.81 \\
Feb & 1.85 & 4.26 & 2.02 & 6.33 & 1.91 & 6.51 \\
Mar & 1.69 & 4.35 & 2.10 & 6.23 & 1.91 & 6.74 \\
Apr & 1.78 & 3.07 & 2.43 & 4.59 & 1.99 & 4.58 \\
May & 1.75 & 3.99 & 2.31 & 5.90 & 1.96 & 6.25 \\
Jun & 1.71 & 4.23 & 2.02 & 6.33 & 1.96 & 6.79 \\
Jul & 1.52 & 3.64 & 1.96 & 5.33 & 1.67 & 5.72 \\
Aug & 1.80 & 3.93 & 2.37 & 5.50 & 2.21 & 6.28 \\
Sep & 1.82 & 3.61 & 2.37 & 5.14 & 2.17 & 5.80 \\
Oct & 1.92 & 2.78 & 2.80 & 4.62 & 2.09 & 4.29 \\
Nov & 2.11 & 3.38 & 2.74 & 4.99 & 2.43 & 5.84 \\
Dec & 1.78 & 3.30 & 2.52 & 5.36 & 1.90 & 5.61 \\
\hline
\end{tabular}

Table 6

Technical data of wind machines [41]

\begin{tabular}{ccccccc}
\hline $\begin{array}{c}\text { Wind } \\
\text { machine }\end{array}$ & $\begin{array}{c}\text { Cut-in } \\
\text { speed } \\
(\mathbf{m} / \mathbf{s})\end{array}$ & $\begin{array}{c}\text { Cut-out } \\
\text { speed } \\
(\mathbf{m} / \mathbf{s})\end{array}$ & $\begin{array}{c}\text { Rated } \\
\text { output } \\
\mathbf{( k W )}\end{array}$ & $\begin{array}{c}\text { Rated wind } \\
\text { speed (m/s) }\end{array}$ & $\begin{array}{c}\text { Hub } \\
\text { height } \\
\mathbf{( m )}\end{array}$ & $\begin{array}{c}\text { Rotor } \\
\text { diameter } \\
(\mathbf{m})\end{array}$ \\
\hline WT 1 & 3 & 25 & 3300 & 12 & 117 & 126 \\
WT 2 & 3 & 22.5 & 3000 & 12 & 119 & 126 \\
WT 3 & 4 & 23 & 2600 & 15 & 75 & 100 \\
WT 4 & 3 & 25 & 2000 & 11.5 & 80 & 110 \\
WT 5 & 4 & 20 & 1800 & 12 & 80 & 100 \\
\hline
\end{tabular}


Table 7

Wind speed at different hub heights, the power curve data and power output from selected wind machines.

\begin{tabular}{|c|c|c|c|c|c|c|c|c|c|c|c|c|c|c|}
\hline \multirow[b]{2}{*}{$\begin{array}{l}\text { Wind } \\
\text { Speed } \\
(\mathrm{m} / \mathrm{s})\end{array}$} & \multicolumn{4}{|c|}{ Number of hours/year } & \multicolumn{5}{|c|}{ Power curve data (kW) } & \multicolumn{5}{|c|}{ Energy Calculations (kWh) } \\
\hline & $75 m$ & $80 \mathrm{~m}$ & $117 m$ & $119 m$ & $\begin{array}{c}\text { WT } 5 \\
1.8 \mathrm{MW}\end{array}$ & $\begin{array}{l}\text { WT } 4 \\
2 \mathrm{MW}\end{array}$ & $\begin{array}{l}\text { WT } 3 \\
2.6 \mathrm{MW}\end{array}$ & $\begin{array}{l}\text { WT } 2 \\
\text { 3MW }\end{array}$ & $\begin{array}{c}\text { WT } 1 \\
\text { 3.3MW }\end{array}$ & $\begin{array}{c}\text { WT } 5 \\
1.8 \mathrm{MW}\end{array}$ & $\begin{array}{l}\text { WT } 4 \\
2 \mathrm{MW}\end{array}$ & $\begin{array}{c}\text { WT } 3 \\
2.6 \mathrm{MW}\end{array}$ & $\begin{array}{l}\text { WT } 2 \\
3 \mathrm{MW}\end{array}$ & $\begin{array}{c}\text { WT } 1 \\
\text { 3.3MW }\end{array}$ \\
\hline 0 & 143 & 143 & 126 & 126 & 0 & 0 & 0 & 0 & 0 & 0 & 0 & 0 & 0 & 0 \\
\hline 1 & 818 & 804 & 725 & 720 & 0 & 0 & 0 & 0 & 0 & 0 & 0 & 0 & 0 & 0 \\
\hline 2 & 1132 & 1094 & 923 & 919 & 0 & 0 & 0 & 0 & 0 & 0 & 0 & 0 & 0 & 0 \\
\hline 3 & 1217 & 1189 & 1031 & 1023 & 0 & 23 & 11 & 14 & 20 & 0 & 27357.56 & 13391.92 & 14315.52 & 20610.53 \\
\hline 4 & 1269 & 1245 & 1063 & 1063 & 89 & 140 & 116 & 179 & 162 & 110843.76 & 174360.97 & 147252.76 & 190190.71 & 172127.90 \\
\hline 5 & 1272 & 1247 & 1132 & 1112 & 228 & 314 & 239 & 416 & 395 & 284414.67 & 391693.89 & 304107.49 & 462797.39 & 447331.20 \\
\hline 6 & 1049 & 1072 & 1048 & 1052 & 424 & 549 & 432 & 712 & 694 & 454322.12 & 588261.43 & 452960.40 & 748685.17 & 726979.44 \\
\hline 7 & 717 & 748 & 872 & 874 & 688 & 900 & 717 & 1148 & 1,060 & 514388.18 & 672891.52 & 513854.63 & 1002892.5 & 923898.63 \\
\hline 8 & 527 & 562 & 693 & 691 & 1034 & 1347 & 1093 & 1713 & 1,714 & 580843.05 & 756668.84 & 575744.66 & 1183138.6 & 1187252.63 \\
\hline 9 & 305 & 327 & 512 & 527 & 1440 & 1775 & 1479 & 2219 & 2,432 & 470668.49 & 580164.29 & 450883.15 & 1168872.2 & 1244619.68 \\
\hline 10 & 130 & 142 & 279 & 288 & 1716 & 1972 & 1817 & 2566 & 2,999 & 243566.09 & 279902.29 & 236095.67 & 738677.29 & 836344.93 \\
\hline 11 & 76 & 76 & 165 & 165 & 1794 & 1999 & 2102 & 2858 & 3,260 & 136284.30 & 151857.47 & 159682.05 & 471354.28 & 537653.94 \\
\hline 12 & 55 & 59 & 78 & 85 & 1800 & 2000 & 2362 & 3000 & 3,300 & 106150.18 & 117944.64 & 129857.47 & 254889.72 & 257281.20 \\
\hline 13 & 31 & 32 & 60 & 61 & 1800 & 2000 & 2504 & 3000 & 3,300 & 57568.97 & 63965.52 & 77584.24 & 182908.80 & 197904.17 \\
\hline 14 & 13 & 15 & 32 & 31 & 1800 & 2000 & 2584 & 3000 & 3,300 & 26994.82 & 29994.24 & 33568.95 & 92952.36 & 105543.11 \\
\hline 15 & 5 & 5 & 13 & 15 & 1800 & 2000 & 2600 & 3000 & 3,300 & 9003.53 & 10003.92 & 13005.10 & 44991.36 & 42870.56 \\
\hline 16 & 1 & 1 & 6 & 6 & 1800 & 2000 & 2600 & 3000 & 3,300 & 1797.55 & 1997.28 & 2596.46 & 18001.80 & 19801.98 \\
\hline 17 & 0 & 0 & 4 & 4 & 1800 & 2000 & 2600 & 3000 & 3,300 & 0.00 & 0.00 & 0.00 & 11983.68 & 13182.05 \\
\hline \multirow[t]{3}{*}{18} & 0 & 0 & 1 & 1 & 1800 & 2000 & 2600 & 3000 & 3,300 & 0.00 & 0.00 & 0.00 & 2995.92 & 3295.51 \\
\hline & \multicolumn{9}{|c|}{ Power output per year ( kWh) } & 2996845.69 & 3847063.85 & 3110584.94 & 6589647.41 & 6736697.439 \\
\hline & \multicolumn{9}{|c|}{ Plant capacity factor $\%$} & 19 & 22 & 13.6 & 25 & 23.3 \\
\hline
\end{tabular}

